\title{
Thermoelectric Materials: Current Status and Future Challenges
}

\author{
Peter A. Finn ${ }^{1}$, Ceyla Asker ${ }^{2}$, Kening Wan $^{2}$, Emiliano Bilotti ${ }^{2}$, Oliver Fenwick ${ }^{2}$ and \\ Christian B. Nielsen ${ }^{1 *}$ \\ ${ }^{1}$ Department of Chemistry, Queen Mary University of London, London, United Kingdom, ${ }^{2}$ School of Engineering and Materials \\ Science, Queen Mary University of London, London, United Kingdom
}

Keywords: thermoelectrics, perovskites, composites, organic semiconductors, doping, organic thermoelectrics

\section{INTRODUCTION}

Net zero refers to the balance of the amount of greenhouse gas emissions produced and the amount removed from the atmosphere, and many companies and states have committed themselves to net zero targets. In June 2019, the United Kingdom became the first major economy in the world to pass a net zero emissions law. This ambitious target aims to reduce the UK's net emissions of greenhouse gases by 100 per cent relative to 1,990 levels by 2,050 and replaces the UK's previous target to reduce emissions by at least $80 \%$. Sweden, France, Denmark, New Zealand and Hungary have also now succeeded in putting net zero targets into law (Net Zero Emissions Race, 2020).

Progress towards these net zero goals has so far been slow. For example, the United Kingdom is behind on even the original $80 \%$ target, and achieving the current aim by 2,050 will be challenging. One thing that is clear to the scientific community is that improvements in technology between now and 2,050 will be key to bring the net zero target within reach. However, this will only happen if we can identify technologies for accelerated development and invest in them now, so we can deliver benefits before the 2,050 deadline. There are multiple areas where new technologies can assist in energy generation and storage, including photovoltaics, wind and water turbines, the hydrogen economy, caloric materials and batteries, as well as energy saving technologies such as low loss electronics. Thermoelectric energy conversion materials were identified by the Henry Royce Institute and the Institute of Physics as a key area of materials research for achieving net zero emissions in the Materials for the Energy Transition (2019) report.

Space heating and cooling (e.g., central heating or air conditioning), is one of the main contributors to emissions and accounts for around $17 \%$ of the UK's $\mathrm{CO}_{2}$ emissions (Department for Business, Energy and industrial Strategy, 2018). In Saudi Arabia, one of the hottest and driest countries in the world, more than $70 \%$ of the kingdom's electricity produced per year is consumed purely for air conditioning and cooling purposes, with the demand doubling during the summer (Demirbas et al., 2017). This home water and space heating is typically achieved through burning natural gas in countries with access to natural gas, and through electrically-powered airsource heat pumps elsewhere. More widespread deployment of air-source heat pumps creates increased electricity demand, so solar-integrated heat pumps are also being investigated as another potential alternative to meet current space heating and domestic hot water demands with a reduced draw from the grid. However, these pumps use refrigerants such as HFCs, which are powerful greenhouse gases, so heat pumps that use other types of materials, such as thermoelectric and caloric materials need to be investigated as "greener" options.

Thermoelectric materials use temperature differences to generate electrical energy. They can therefore provide fully electric heating and cooling technology without moving parts or refrigerants. Another advantage of this technology is that it can be used to harvest waste heat from other processes and convert it directly into electricity. As about two thirds of primary energy are wasted as heat (Lawrence Livermore National Laboratory Estimated U.S, 2019) technologies, such as 
thermoelectrics, that can recover this waste will be important for achieving the world's net zero emission goals. This is most readily extracted in high temperature industrial settings, but it is estimated that $49 \%$ of the energy input in the residential sector is lost, almost entirely in the form of heat (Forman et al., 2016).

Current thermoelectric devices are robust and the technology has already been applied in niche applications such as within the aerospace sector (Freer and Powell, 2020). However, wider adoption and technology is being held back due to the low efficiency of current thermoelectric devices, as well as the sustainability of state-of-the-art materials (Patyk, 2010). In order for thermoelectric technology to expand into non-niche areas, it needs to be ensured that it can compete on efficiency with incumbent technologies. This will require a concerted effort in developing new sustainable materials with high thermoelectric performance, engineering the nanoscale interfaces in the materials and engineering the devices themselves.

Whilst the challenge is huge, the opportunity for nations and companies in this sector is also huge. There are a large number of new thermoelectric materials are being developed, and the market for thermoelectric technology is growing (Harrop and Das, 2020). Therefore, now is an ideal time to capture this momentum and expand the role of thermoelectric technology in society and take us closer to net zero.

The primary way to increase sustainability is to improve the efficiency of devices, and from a materials perspective, this means improving the figure of merit, $z T$, of the thermoelectric materials deployed. The dimensionless $z T$ is directly proportional to the squared Seebeck coefficient (S) and the electrical conductivity $(\sigma)$, which together comprise the power factor $\left(P F=S^{2} \sigma\right)$, directly proportional to the temperature $(\mathrm{T})$ and inversely proportional to the thermal conductivity $(\kappa)$. There are now materials with $z T>1$ from room temperature (Poudel et al., 2008) to $1,000^{\circ} \mathrm{C}$ (Paik et al., 2011), and $z T \geq 2.5$ has been recorded in $\mathrm{PbTe}$ (Tan et al., 2016) and SnSe (Zhao et al., 2014; Chang et al., 2018) alloys. Materials with $z T_{\text {average }} \approx 1$ would require a temperature difference across the device of $\Delta \mathrm{T}>250 \mathrm{~K}$ to achieve a $10 \%$ conversion efficiency, whereas deployment of materials with $\mathrm{zT}_{\text {average }} \approx 2$ would only require $\Delta \mathrm{T}>150 \mathrm{~K}$ to achieve the same $10 \%$ conversion efficiency. However, to compete on efficiency with other technologies, such as Rankine cycles, a $z T$ of at least four is required (Vining, 2009). This sets a huge materials challenge.

The chalcogenides have perhaps been the most widely explored class of thermoelectric material to date. $\mathrm{Bi}_{2} \mathrm{Te}_{3}$ and its alloys are the most widely deployed, despite concerns about the long-term availability of tellurium, with $z T$ up to 1.4 in the $<200^{\circ} \mathrm{C}$ regime (Poudel et al., 2008). PbTe alloys have the additional issue of $\mathrm{Pb}$ toxicity but have been widely deployed in the space sector (Lalonde et al., 2011) due to a remarkably high $z T$ that can reach 2.5 (Tan et al., 2016). The sulphides have not offered quite the same maximum performance as the other chalcogenides, but elemental abundance is an advantage in materials such as $\mathrm{Cu}_{2} \mathrm{~S}$ which show $z T \sim 1$ (Ge et al., 2018; Mikuła et al., 2020) Half-Heuslers (Joshi et al., 2014; Zhou et al., 2018), clathrates (Deng et al., 2010), and skutterudites (Rogl et al.,
2015; Rogl and Rogl, 2019) have all shown $z T \geq 1$, whilst oxides and $\mathrm{SiGe}$ offer good performance at high temperature (Nozariasbmarz et al., 2017).

A programme of materials discovery will likely find significant improvements in $z T$ within these classes of materials, but it is worth considering where else substantial increases in $z T$ may come from. Zintl phases are one such group of materials. Defined by their mixed ionic and covalently bonded structures, and including $\mathrm{Yb}_{1} \mathrm{Zn}_{2} \mathrm{Sb}_{2}(z T=0.55)$ (Gascoin et al., 2005), $\mathrm{Yb}_{14} \mathrm{MnSb}_{11}(z T=1)$ (Brown et al., 2006; Paik et al., 2011), and $\mathrm{Mg}_{3} \mathrm{Sb}_{1.5} \mathrm{Bi}_{0.5},(z T=1.6)$ (Zhang et al., 2017) these materials show electron crystal phonon glass behaviour with the low thermal conductivity driven by complex unit cells and strongly anharmonic bonding. Interestingly, they can form crystals with $3 \mathrm{D}, 2 \mathrm{D}, 1 \mathrm{D}$, and $0 \mathrm{D}$ structure.

Other interesting routes to explore include the spin Seebeck effect (Sierra et al., 2018) as well as the use of topological states (Xu et al., 2017; Fu et al., 2020), and non-Wiedemann Franz materials (Scheunemann and Kemerink, 2020) that exhibit low electronic thermal conductivity. Compositionally graded materials (Cramer et al., 2018; Ou et al., 2020) can achieve a large $z T_{\text {average }}$ by connecting in series, a composition with highperformance at high temperatures with a composition with highperformance at low temperatures.

A second approach to improving the sustainability of thermoelectric devices is to focus on the embedded energy, abundance and toxicity of the thermoelectric materials themselves. There is therefore a parallel search for materials that can be processed at lower temperatures, which are made from abundant elements and in many cases can be printed. This has led to an interest in several new classes of thermoelectric materials: organics (Cowen et al., 2017), 2D materials (including graphene) (Li et al., 2020), carbon nanotubes (Zhou et al., 2017; Ichinose et al., 2019; Statz et al., 2020), polymer-carbon composites (Cho et al., 2016b), halide perovskites (Liu et al., 2019b), and metal organic frameworks (Erickson et al., 2015; Sun et al., 2017) to name a few. This study discusses a few examples of these thermoelectric materials in more detail below.

\section{SEMICONDUCTING POLYMERS}

\section{High Performing Materials}

While this study focuses on organic semiconducting polymers, significant research also centres on small molecules organic semiconductors. Zhang et al. recently explored high mobility organic semiconductors for thermoelectrics (Zhang and Di, 2020). Many different $\mathrm{p}$ - and n-type organic materials have been used for thermoelectric studies including, poly (3hexylthiophene) (P3HT, Figure 1A), poly [2,5-bis (3alkylthiophen-2-yl) thieno $[3,2-b]$ thiophene] (PBTTT, Figure 1A), diketopyrrolopyrrole (DPP) derivatives, poly (3,4ethylenedioxythiophene) (PEDOT) and naphthalenediimide (NDI) derivatives. Polythiophenes including, P3HT and PBTTT, are the most widely researched p-type organic polymers for thermoelectric applications due to simple synthetic routes and reasonable air stability (Nielsen and 

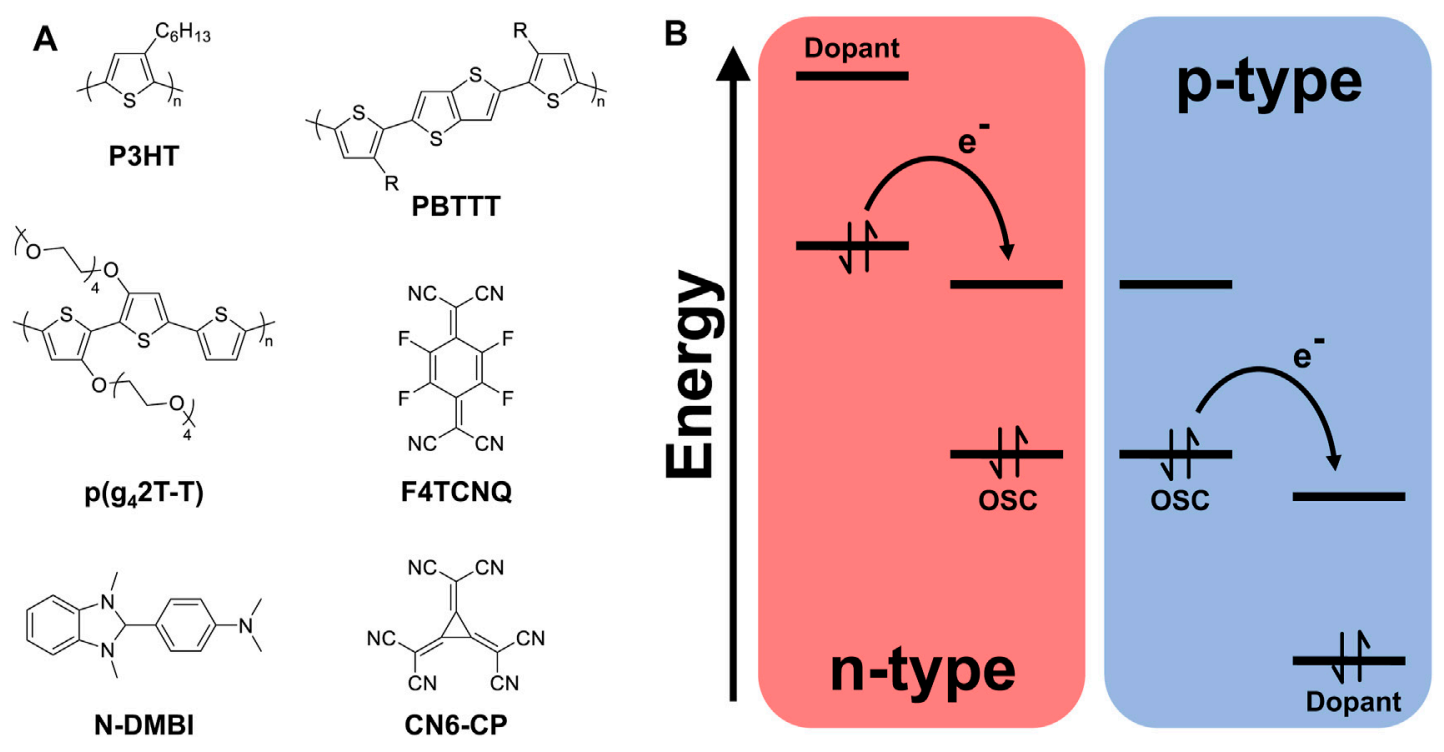

FIGURE 1 | (A) Examples of semiconducting polymers and dopants investigated for thermoelectric applications; (B) Frontier energy diagrams illustrating n- and p-type doping of an organic semiconductor (OSC) by charge transfer from a chemical dopant molecule.

McCulloch, 2013). The p-type dopant 2,3,5,6-tetrafluoro-7,7,8,8tetracyanoquinodimethane (F4TCNQ, Figure 1A) is commonly used to improve electrical conductivity. P3HT and F4TCNQ were first blended in solution to increase performance of thin film transistors however, charge transfer in solution leads to aggregation where the newly charged species precipitate out of the processing solvent (Ma et al., 2008). Thermoelectric devices fabricated from these solutions produce inhomogeneous films where the highest power factor (PF) of $0.4 \mu \mathrm{W} \mathrm{m}{ }^{-1} \mathrm{~K}^{-2}$ has been reported for blended solutions (Lim et al., 2018). Scholes et al. then showed that the solution-sequential processing (SqP) of P3HT films with F4TCNQ in an orthogonal solvent led to much higher conductivities (Scholes et al., 2015). The method requires spin coating of a semi-crystalline polymer film from a chosen solvent, depositing a solution of dopant material for an allotted time and finally spinning off the excess solution. Passivation of the dopant through the semi-crystalline polymer film allows for efficient doping and using an orthogonal solvent, such as acetonitrile, prevents disruption to morphology. Jacobs et al. showed that this method can be used with a variety of electron acceptors in different solvents on P3HT and PBTTT (Jacobs et al., 2016). In addition to SqP, F4TCNQ vapour doping has afforded high thermoelectric properties with PBTTT (Kang et al., 2016, 2019). Patel et al. evaporated F4TCNQ into PBTTT thin films achieving a large PF of $120 \mu \mathrm{Wm}^{-1} \mathrm{~K}^{-2}$ from a high electrical conductivity of $670 \mathrm{~S} \mathrm{~cm}^{-1}$ (Patel et al., 2017). A new class of isoindoloindole-based p-type polymers have also been used for thermoelectric applications reaching a PF of $35 \mu \mathrm{W} \mathrm{m}{ }^{-1}$ $\mathrm{K}^{-2}$ by SqP thin films with F4TCNQ solutions (Yoon et al., 2020a). $\operatorname{Poly}\left(2-\left(\left[2,2^{\prime}\right.\right.\right.$-bithiophen $]-5$-yl)-3,8-di-fluoro-5,10-bis (5-octylpentadecyl)-5,10-dihydroindolo[3,2-b]indole)) (PIDFBT) utilises the electron rich isoindoloindole motif for charge transfer to the F4TCNQ electron acceptor and the addition of fluorine atoms increases planarity through favourable $\mathrm{F}-\mathrm{H}$ interactions, leading to electrical conductivities over $210 \mathrm{~S}$ $\mathrm{cm}^{-1}$ (Park et al., 2019). DPP polymers have also been considered as high-performing $\mathrm{p}$ - and n-type thermoelectric materials. Donor-acceptor derivatives using thiophene-flanked DPP motifs have shown promise with a PF of $276 \mu \mathrm{W} \mathrm{m}{ }^{-1} \mathrm{~K}^{-2}$ recorded for PDPP3T SqP-doped with $\mathrm{FeCl}_{3}$ (Jung et al., 2017) Liu et al. have also shown to increase the PF and electrical conductivity of PDPP5T by replacing one thiophene unit with a more electron rich 3,4-ethylenedioxythiophene (EDOT) to improve unfavourable energetics, increasing the PF markedly from 11 to $298 \mu \mathrm{W} \mathrm{m}{ }^{-1} \mathrm{~K}^{-2}$ (Liu Z. et al., 2020).

By flanking with the electron-deficient pyrazine and copolymerising with cyano-functionalised bithiophene monomers, the electron-deficient DPP moiety has also been employed for n-type thermoelectric applications (Yan et al., 2019). Compared to a thiophene-flanked derivative of the same co-polymer, Yan et al. showed that incorporation of pyrazine improves the n-type doping efficiency via increasing the energetic offset leading to a PF of $57.3 \mu \mathrm{W} \mathrm{m}{ }^{-1} \mathrm{~K}^{-2}$ when doped with 4-(2,3-Dihydro-1,3-dimethyl-1H-benzimidazol-2yl)- $N, N$-dimethylbenzenamine (N-DMBI, Figure 1A) as a hydride source. However, the highest PF recorded for an n-type organic thermoelectric material utilises the thiophene flanked benzodifurandione oligo ( $p$-phenylenevinylene) (BDOPV) motif co-polymerised with thiophene to produce TBDOPV-T, resulting in maximum PF of $106 \mu \mathrm{Wm}^{-1} \mathrm{~K}^{-2}$ when doped with N-DMBI (Lu et al., 2021). Interestingly, the vinyl derivative of the same polymer (TBDPPV) exhibited a higher maximum electrical conductivity of $90 \mathrm{~S} \mathrm{~cm}$ compared to TBDOPV-T, however, the optimal recorded PF is slightly lower with a value of $76 \mu \mathrm{W} \mathrm{m}{ }^{-1} \mathrm{~K}^{-2}$ but is still among the highest performing n-type organic polymers to date. In terms of 
$z T$, which is less frequently reported for organic materials than the power factor, due to the challenges associated with accurately measuring the thermal conductivity, the current best performing organic thermoelectric materials have $z T$-values of 0.42 (p-type) (Kim et al., 2013) and 0.34 (n-type) (Liu J. et al., 2020) at room temperature and $120^{\circ} \mathrm{C}$, respectively.

\section{Ongoing Materials Development and Future Directions}

Although the examples highlighted above show the capabilities of organic semiconductors for thermoelectric applications, important ongoing research into the structure-function relationships of host and dopant to promote dopant stability and efficiency is still crucial for further understanding and improvement in performance. Recently, the engineering of semiconducting polymers to increase the stability of the dopant within the polymer matrix has been a particular focus point (Li et al., 2016; Kroon et al., 2017; Hofmann et al., 2018). A well-explored strategy in this pursuit is to introduce more polar side chains than the archetypical alkyl chains that dominate semiconducting polymer design, hypothesising stronger interactions between charged dopant species and the organic semiconductor. A common motif utilised is ethylene glycol (EG), which has been used by several groups. Kroon et al. showed that polythiophene with tetraethylene glycol side chains, $\mathrm{p}\left(\mathrm{g}_{4} 2 \mathrm{~T}-\mathrm{T}\right.$, Figure 1A), has enhanced thermal stability compared to P3HT when doped with F4TCNQ (Kroon et al., 2017). By measuring the electrical conductivity as a function of temperature, at $\sim 100^{\circ} \mathrm{C}$ a decrease is observed for P3HT whereas $\mathrm{p}\left(\mathrm{g}_{4} 2 \mathrm{~T}-\mathrm{T}\right)$ displays stable conductivity up to $180^{\circ} \mathrm{C}$. They hypothesise that the polar side chain interacts with F4TCNQ anions preventing a reduction in performance at high temperature due to diffusion of dopant species within the film. However, the addition of oligoethylene glycol chains to the polymer backbone must be considered with care as improvement is not always observed. A study by Dong et al. revealed that the introduction of a methylene spacer between the first side chain oxygen and polymer backbone reduces thermal dopant stability observed through the loss in conductivity at $130{ }^{\circ} \mathrm{C}$ when comparing to the same polymer with the EG motif directly bonded to the backbone (Dong et al., 2020). This has also been observed for another series of EGfunctionalised derivatives of $\mathrm{P} 3 \mathrm{HT}$ where the thermal stability at $80^{\circ} \mathrm{C}$ decreased with increasing polar co-monomer content (Finn et al., 2020).

EG motifs have also been added to NDI derivatives to improve the electrical conductivity of n-type polymers. Recently Shin et al. showed the synthesis of a branched oligoethylene glycol NDI derivative that showed thermoelectric properties when doped with the benzimidazole-based n-type dopant N-DiPrBI (Shin et al., 2020). Although lower thermoelectric performance was exhibited when compared to other n-type thermoelectric materials, they showed that the maximum PF was recorded at a low $\mathrm{N}-\mathrm{DiPrBl}$ concentration of $1-2 \mathrm{wt} \%$, whereas commonly a higher dopant concentration is required, an improvement attributed to the incorporation of EG into the side chain. An interesting case of introducing polarity to NDI derivatives is utilising amphiphilic side chains to tailor dopant location with respect to the polymer backbone. Liu et al. synthesised two NDI monomers, one with triethylene glycol (TEG) side chains and the other with a C8 alkyl spacer before the TEG motif, labelled NDI2TEG and NDI2C8TEG respectively (Liu et al., 2021). After co-polymerisation with an alkoxy-bithiazole monomer (2Tz) and doping thin films with N-DMBI, both polymers exhibited similar electrical conductivities. However, the alkylspacer containing polymer revealed a Seebeck coefficient double that of the NDI2TEG-based polymer and a PF of $16.5 \mu \mathrm{W} \mathrm{m} \mathrm{m}^{-1}$ $\mathrm{K}^{-2}$, the highest reported value for NDI-based materials. Using kinetic Monte Carlo simulations, the authors attribute the higher Seebeck coefficient to reduced coulombic interactions from the larger host-dopant distance.

Low band gap polymers containing heavier chalcogens have proven to be interesting for $\mathrm{TE}$ applications. Heeney et al. synthesised the regioregular analogue of P3HT, poly(3hexylselenophene) (P3HS), replacing sulphur with selenium (Heeney et al., 2007). Thin film UV-Vis absorption spectra reveal a large red-shift indicating a smaller band gap energy, which is attributed to increased backbone planarity as modelled using DFT by Wijsboom et al. (2009). Selenium is less electronegative than sulphur, which also leads to a decrease in ionisation potential that is preferable for donating electrons to an electron acceptor (Patra and Bendikov, 2010). Scholes et al. studied the effect of increasing selenophene content in the copolymer P37S-stat-P3HT and found the ionisation potential to decrease with increasing 3-heptylselenophene content (Scholes et al., 2019). When doped with F4TCNQ via SqP, charge carrier concentration only increases a small amount across the series whereas conductivity increases dramatically with increasing selenophene content. Using Hall Effect measurements, they found that the conductivity increase arises from increased Hall mobility due to increased crystallinity. Gregory et al. and Panchuk et al. took a different approach by synthesising a series of poly(3-alkylchalcogenophenes) with sulphur, selenium and tellurium and 3,7-dimethyloctyl as the side chain (Gregory et al., 2018; Panchuk et al., 2019). Dip-doping in low concentrations of $\mathrm{FeCl}_{3}$ and $\mathrm{Fe}(\mathrm{Tos})_{3}$ revealed moderate doping efficiencies and electrical conductivities when moving down group 16, showing that using the heavier chalcogens is a promising strategy to increase electrical conductivity. However, the most impressive use of sulphur replacement for thermoelectric applications is the DPP derivative PDPPSe-12 (Ashraf et al., 2015; Ding et al., 2019). PDPPSe-12 doped with $\mathrm{FeCl}_{3}$ exhibits a conductivity and power factor of $997 \mathrm{~S} \mathrm{~cm}^{-1}$ and $348 \mu \mathrm{W} \mathrm{m} \mathrm{m}^{-1} \mathrm{~K}^{-2}$ respectively, due to excellent charge carrier mobilities. Using the combination of heavy atom substitution and side chain engineering, field-effect hole mobilities of $9.4 \mathrm{~cm}^{2} \mathrm{~V}^{-1} \mathrm{~s}^{-1}$ have been reported for PDPPSe-12 demonstrating the importance of investigating and optimising chemical and morphological structure in organic thermoelectric materials (Wang et al., 2018).

Designing molecular dopants with improved doping efficiency and stability is as important as enhancing the properties of the organic semiconductor for thermoelectric applications, and the two main types of molecular doping are acid/base and 
reduction/oxidation reactions. P-type acid (n-type basic) doping requires proton (hydride) transfer from an acid (base) to an organic semiconductor, a process that has been shown to work through both co-processing and $\mathrm{SqP}$ techniques. The polar side chain functionalised $\mathrm{p}\left(\mathrm{g}_{4} 2 \mathrm{~T}-\mathrm{T}\right)$, co-processed with various sulphuric acids, exhibits conductivities up to $120 \mathrm{~S} \mathrm{~cm}$ facilitated by proton transfer, as explored in a study by Hofmann et al. (2018). This study also found that 1,3propanedisulfonic acid doped $\mathrm{p}\left(\mathrm{g}_{4} 2 \mathrm{~T}-\mathrm{T}\right)$ thin films retain conductivity at $120^{\circ} \mathrm{C}$ for $20 \mathrm{~h}$, indicating the high thermal stability of acid doping in combination with the polar side chains. The most employed n-type doping system employs organic semiconductors with large electron affinities, sequentially doping them with n-type dopants such as $\mathrm{N}$-DMBI and N-DPBI exploiting hydride transfer between the dopant and semiconductor (Naab et al., 2013). The other approach for molecular doping utilises redox reactions between electron donor and acceptor molecules for $\mathrm{n}$ - and p-type doping, as illustrated in Figure 1B (Jacobs and Moulé, 2017). For n-type doping, designing electron rich molecules to create an energetic route for charge transfer from the highest occupied molecular orbital (HOMO) of the dopant to the lowest unoccupied molecular orbital (LUMO) of the semiconductor is usually accomplished by introducing highly electron-donating groups onto the dopant. On the other hand, p-type dopants have deep-lying LUMO energy levels, allowing charge transfer to occur from the semiconductor's higher lying HOMO, and are typically designed by introducing highly electron-withdrawing groups. Two examples of this are tetrakis (dimethylamino) ethylene (TDAE), a reducing agent (n-type dopant), and F4TCNQ, an oxidising agent (p-type dopant). TDAE has four electrondonating dimethylamino moieties increasing electron density on the $\mathrm{C}=\mathrm{C}$ double bond, which in turn raises the frontier orbitals. On the other hand, F4TCNQ has two malononitrile groups in the 1- and 4-positions and four fluorine atoms in the other positions of the benzoquinone ring. These groups are strongly electron-withdrawing, which results in a highly electron-deficient molecule. Chemical design can be used to control the frontier energy levels of both the organic semiconductor and the dopant (Bronstein et al., 2020). A remarkable example was given by Kiefer et al. (2019), who showed that increasing the electron density on a polythiophene led to energetics so favourable with a strong p-type dopant that two electron transfers occur, effectively double-doping the polymer.

$$
E(\delta)=(I P-E A) \delta-k \frac{e^{2}}{r} \delta^{2}
$$

The formation of an ion pair after charge transfer can be described by the ion pair energy $\mathrm{E}(\delta)$ shown in Equation 1, where $\delta$ is the degree of charge transfer, $r$ is the separation between electron and hole, $k$ is the Coulomb's constant, $e$ is the electric charge and IP and EA are the ionisation potential and electron affinity, respectively (Torrance et al., 1981; Jacobs and Moulé, 2017). The equation describes the energy to form an ion pair and arises from the free energy of ionisation between the donor and acceptor (IP-EA) and Coulombic interaction between the electron and hole, quantified by the electrostatic energy (Madelung energy) $\left(\mathrm{ke}^{2} / \mathrm{r}\right)$. The degree of charge transfer also plays a role in ion pair formation. With $\delta=1$ denoting complete transfer of charge, referred to as integer charge transfer, while $\delta<1$ indicate that charge transfer complexes can form. Charge transfer complexes form when the HOMO of the donor and the LUMO of the acceptor hybridise forming new local "bonding" and "antibonding" states and the charge is shared by the dopant and the semiconductor. Méndez et al. compared doping of quaterthiophene (4T) and P3HT with F4TCNQ and found that 4T:F4TCNQ forms charge transfer complexes whereas integer charge transfer occurs for P3HT:F4TCNQ. (Méndez et al., 2015) UV-Vis absorption spectroscopy revealed optical transitions between the bonding and antibonding orbitals of the charge transfer complex, while no F4TCNQ radical anion peaks were observed ruling out ion pair formation. Comparing the $\mathrm{C} \equiv \mathrm{N}$ stretches of doped films to F4TCNQ radical anions using infra-red (IR) spectroscopy, they revealed a resonance frequency shift depending on the degree of charge transfer. This useful tool for analysing semiconductor: F4TCNQ systems have also been used in the assignment of integer charge transfer and charge transfer complex states in F4TCNQ doped PBTTT films by Zapata-Arteaga et al., who investigated how the degree of charge transfer affected thermal stability (Zapata-Arteaga et al., 2020). Upon controlling the substrate temperature during the vapour doping of PBTTT thin films with F4TCNQ, they were able to control the degree of charge transfer complex states and thus explore the electrical and thermal conductivities along with the Seebeck coefficients. They found that films rich in charge transfer complex states are more thermally stable when exposed to $100{ }^{\circ} \mathrm{C}$ for $10 \mathrm{~h}$ as compared to high integer charge transfer fractions and utilising a moderate degree of charge transfer complex states also led to good thermoelectric performance.

Doping efficiency also needs to be considered as the formation of an ion pair and does not directly lead to high electrical conductivities. After charge transfer from the organic semiconductor to the dopant (p-type), the newly formed polaron must escape the Coulombic trap of the ion pair to become a free charge carrier. Aubry et al. showed that large dodecaborane-based dopants ( $2 \mathrm{~nm}$ in size) can electrostatically shield counter anions from polarons formed upon doping P3HT (Aubry et al., 2019). They also tune the doping strength of the dodecaborane-based dopants achieving an estimated 96\% doping efficiency by optimising the free energy of ionisation and coulombic interaction (Aubry et al., 2020).

Improving dopant miscibility within the polymer matrix has also shown positive results in the literature where the addition of polar groups and side chains has led to increased conductivity. Li et al. showed that monoester substituted F4TCNQ derivatives have greater doping effectiveness due to miscibility with P3HT, although the energetics are less favourable than for the parent F4TCNQ (Li et al., 2015). Saska et al. took the same approach via the substitution of three cyano-groups with methyl esters on the strong oxidant hexacyano-[3]-radialene (CN6-CP, Figure 1A). The ester-functionalised derivative shows solubility and stability 
in halogenated solvents (Saska et al., 2019). Karpov et al. also showed that the radical anion salt of CN6-CP with a tetrabutylammonium counter cation can be solution coprocessed with P3HT in organic solvents (Karpov et al., 2018, 2019, 2020). Co-processing through the blending of semiconductor and dopant usually leads to insoluble materials thus producing inhomogeneous films. However, the addition of alkyl chains to the counter cation leads to enhanced processability and miscibility. Altering molecular dopant size has been shown to influence the electrical performance upon doping due to the position of the dopant within the polymer microstructure. This can be shown by the comparison between two hydride n-type dopants, N-DMBI and a trisaminomethane derivative (Yang et al., 2020). Lu et al. reported a record high n-type power factor of $80 \mu \mathrm{W} \mathrm{m} \mathrm{m}^{-1} \mathrm{~K}^{-2}$ upon doping a BDOPV-based polymer with the trisaminomethane dopant (Lu et al., 2020). They ascribed the high power factor to improved conductivity owing to decreased disorder upon doping. Among other improved characteristics, the dopant cation resides in the side chain whereas N-DMBI sits within the polymer backbone perturbing conjugation and reducing charge transport. Similarly, using a BDOPV-based polymer, Pei and co-workers recently developed an efficient $N$-heterocyclic carbene based n-type dopant generated by thermal decarboxylation of a stable precursor affording an electrical conductivity of $8.4 \mathrm{~S} \mathrm{~cm}^{-1}$ (Ding et al., 2020).

Doping efficiency has also been improved using two new similar methods reported in the literature, anion exchange and cascade doping. Similar to sequential processing techniques, anion exchange doping utilises molecular dopants in concentrated solutions of electrolytes. (Yamashita et al., 2019; Murrey et al., 2021). Deposition of the anionic exchange solution onto a polymer film allows for the reduced p-type dopant to substitute with the anion from the electrolyte, leading to higher doping levels. Yamashita et al. showed that PBTTT doped using anion exchange solutions containing F4TCNQ and LiTFSI as the dopant and electrolyte, respectively, led to conductivities of $620 \mathrm{~S} \mathrm{~cm}^{-1}$ compared to $260 \mathrm{~S} \mathrm{~cm}^{-1}$ for just F4TCNQ. A similar approach has recently afforded conductivities up to $1200 \mathrm{~S} \mathrm{~cm}^{-1}$ again using PBTTT as the semiconductor (Jacobs et al., 2021). Alternatively, Yoon et al. demonstrated the scope of cascade doping whereby SqP firstly with F4TCNQ solutions then secondly with $\mathrm{NOBF}_{4}$ solutions onto thin films of the p-type polymer PIDF-BT (Yoon et al., 2020b). Similar to the anion exchange method, $\mathrm{BF}_{4}$ anions exchange with F4TCNQ anions; increased doping levels ascribed to the low activation energy of the PIDF-BT-F4TCNQ$\mathrm{BF}_{4}$ transition state explain the increased electrical conductivity.

Orientation of semiconducting polymer thin films has also been considered for thermoelectrics, whereby alignment of the polymer crystallites within the film reveals directional thermoelectric characteristics. Brinkmann et al. have carried out extensive work using high-temperature rubbing, whereby heating the polymer film and mechanically rubbing using a micro-fibre cloth attached to a rotating cylinder produces highly oriented polymer films (Hamidi-Sakr et al., 2016). Polarised UV-Vis absorption spectroscopy reveals anisotropic absorption of the $\pi-\pi^{*}$ transition in the parallel direction of rubbing indicative of alignment of crystalline regions. Electron diffraction patterns also show temperature dependent orientation of $\mathrm{P} 3 \mathrm{HT}$ relative to the substrate, where high rubbing temperatures primarily induce face-on orientation. Early work using $\mathrm{SqP}$ of aligned P3HT thins films with F4TCNQ in acetonitrile solutions produced a conductivity and power factor of $22 \mathrm{~S} \mathrm{~cm}^{-1}$ and $8.5 \mu \mathrm{W} \mathrm{m} \mathrm{m}^{-1} \mathrm{~K}^{-2}$, respectively, in the parallel direction. Polarised UV-Vis absorption spectra reveal absorption of F4TCNQ anions in the perpendicular direction and the doped polymer in the parallel direction. Supported by electron diffraction data, they conclude from this observation that F4TCNQ sits between the alkyl side chains, perpendicular to the P3HT backbone (Hamidi-Sakr et al., 2017). High-temperature rubbing on PBTTT also shows anisotropic power factor and electrical conductivity of $100 \mu \mathrm{W} \mathrm{m} \mathrm{m}^{-1} \mathrm{~K}^{-2}$ and $193 \mathrm{~S} \mathrm{~cm}^{-1}$ when doped sequentially with F4TCNQ (Vijayakumar et al., 2019a). They even reported outstanding conductivities of $10^{5} \mathrm{~S} \mathrm{~cm}^{-1}$ and power factors $>2 \mathrm{~mW} \mathrm{~m}^{-1}$. $\mathrm{K}^{-2}$ from highly oriented PBTTT films, using immersive doping in a solution of $\mathrm{FeCl}_{3}$ in nitromethane (Vijayakumar et al., 2019b). However, recently Vijayakumar et al. have shown that the simple change in the $\mathrm{SqP}$ technique using incremental concentration doping can improve the electrical conductivity and $\mathrm{PF}$ of a thermoelectric material (Vijayakumar et al., 2020). When compared to the $920 \mathrm{~S} \mathrm{~cm}^{-1}$ measured via direct doping of aligned PBTTT films with F4TCNQ as the dopant measured in the direction parallel to rubbing, the incremental concentration doped films exhibit an improved conductivity of $1,380 \mathrm{~S} \mathrm{~cm}^{-1}$ highlighting that simple changes in processing methods can lead to vast improvements.

The low electrical conductivity of pristine organic semiconductors is overcome by increasing the charge carrier concentration through chemical doping, although a balance must be struck as the Seebeck coefficient decreases with increasing charge carrier concentration. The chemical doping process is further complicated by the fact that it can compromise the charge carrier mobility due to the structural changes upon doping and that untethered dopants tend to diffuse within and out of the film at elevated temperatures required for energy harvesting.

The above discussion has outlined some of the current challenges in organic thermoelectrics. Much effort is being devoted to addressing these shortcomings from several different angles - including semiconductor optimisation, dopant modifications, new processing and doping strategies, and judicious control of the complicated polymer:dopant microstructure. While great strides are being taken, further progress is still needed in all these aspects in order to realise competitive organic thermoelectric devices.

\section{HALIDE PEROVSKITES}

Halide perovskites have increasingly been the focus of thermoelectric investigation due to their ultralow thermal conductivity, high charge carrier mobility, and high Seebeck coefficient as well as their low cost and ease of fabrication by solution processes (Stoumpos et al., 2013; He and Galli, 2014; 

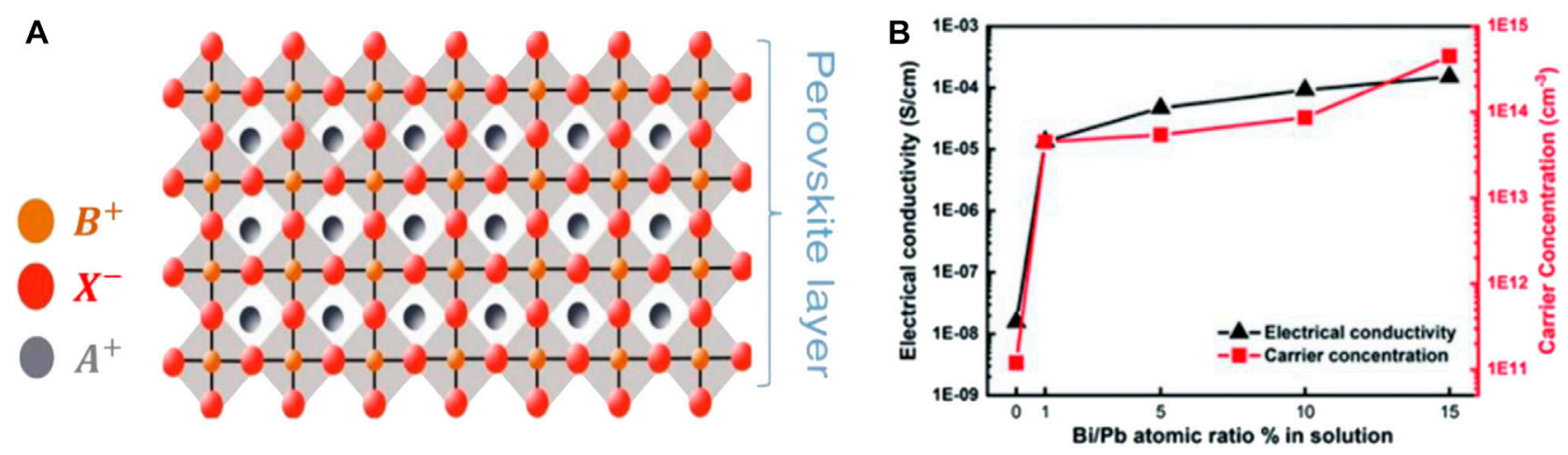

FIGURE 2 | (A) Schematic representation of $\mathrm{ABX}_{3}$ perovskite structure. Reproduced from Liu et al., 2019a; (B) Electrical properties of Bi-doped MAPbBr 3 single crystals. Reprinted from Tang et al., 2020.

Dong et al., 2015; Hata et al., 2016; Yue et al., 2016; Haque et al., 2020). They have the general chemical formula of $\mathrm{ABX}_{3}$ where $\mathrm{A}$ is an organic or inorganic cation (e.g., $\mathrm{Cs}^{+}, \mathrm{CH}_{3} \mathrm{NH}_{3}{ }^{+}$, $\mathrm{NH}_{2} \mathrm{CHNH}_{2}^{+}$), B a metal cation (e.g., $\mathrm{Pb}^{2+}, \mathrm{Sn}^{2+}$ ), and $\mathrm{X}$ a halide anion (e.g., $\mathrm{Cl}^{-}, \mathrm{Br}^{-}$or $\mathrm{I}^{-}$) as illustrated in Figure 2A, and the manipulation of $\mathrm{A}, \mathrm{B}$ and $\mathrm{X}$ sites leads to diverse material properties and unique opportunities (Haque et al., 2020). Inorganic halide perovskites, $\mathrm{CsPbX}, \mathrm{Cs}_{4} \mathrm{PbX}_{6}$, and $\mathrm{CsPb}_{2} \mathrm{X}_{5}$ (X: $\mathrm{Br}$ or $\mathrm{Cl}$ ) were first reported in the 1890s (Wells, 1893), whilst hybrid organic-inorganic halide perovskites were first synthesized in the late 1970s (Weber, 1978). In recent years they have been developed rapidly for photovoltaic devices with single junction efficiency of up to 25.5\% (Best Research-Cell Efficiency Chart, 2021). Additionally, they have been identified as "phonon glass electron crystals" due to the observations of ballistic charge transport and diffusive phonon transports (Miyata et al., 2017). The origin of the phonon glass electron crystal behaviour is the cation on the A-site, which is relatively weakly bonded to the lattice and can rattle and rotate in the perovskite cage structure. Electron and phonon transport is entirely on the metal halide lattice in the halide perovskites, but the anharmonicity caused by motion [in particular rotation (Liu et al., 2019a)] of the A-site cation can scatter the propagating phonons and reduce thermal conductivity into the ultralow regime $\left(<0.5 \mathrm{~W} \mathrm{~m}^{-1} \mathrm{~K}^{-1}\right)$. Recent computational studies have indicated promising thermoelectric applications (Filippetti et al., 2016; Shukla et al., 2020), with predictions of $z T$ up to 2 when the charge carrier density is $\sim 10^{18-19} \mathrm{~cm}^{-3}$ (Lee et al., 2015; Filippetti et al., 2016; Guo and Wang, 2016; Zhao et al., 2017).

Realising this performance with halide perovskites is challenging but some early studies in this area have already achieved promising $z T$ values of up to 0.14 (Lee et al., 2017; Liu et al., 2017; Liu et al., 2019b; Saini et al., 2020). One of the principal challenges is in finding doping strategies to increase carrier concentrations to $\sim 10^{18}-10^{20} \mathrm{~cm}^{-3}$. Experimentally, chemically-induced doping of $\mathrm{CH}_{3} \mathrm{NH}_{3} \mathrm{PbI}_{3}$ and the photoinduced doping of $\mathrm{MASnI}_{3}$ improved $z \mathrm{~T}$ by more than two orders of magnitude (Mettan et al., 2015). Substitutional doping of $\mathrm{CH}_{3} \mathrm{NH}_{3} \mathrm{PbBr}_{3}$ with $\mathrm{Bi}$ has been shown to increase the electrical conductivity by more than three orders of

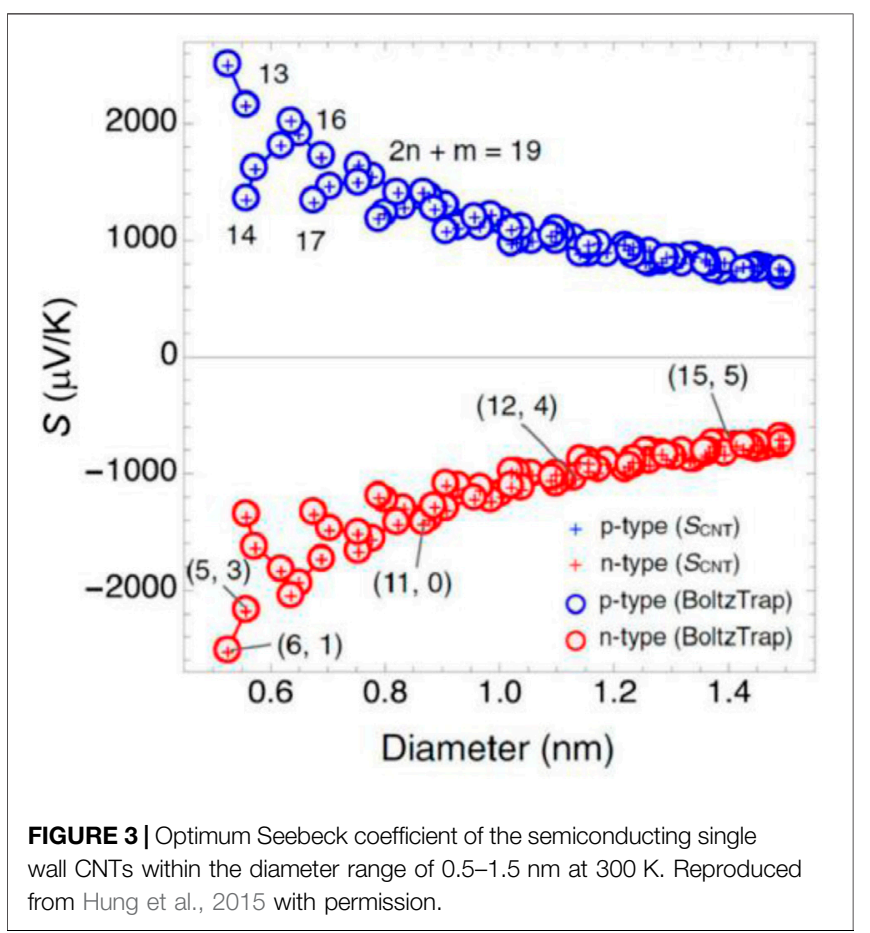

magnitude as shown in Figure 2B (Tang et al., 2020) and modulation of the stoichiometry has also been shown to increase electrical conductivity (Haque et al., 2019). However, in these cases, $z T$ remained low. On the other hand, adjustment of the stoichiometry in the copper based perovskite $\mathrm{C}_{6} \mathrm{H}_{4} \mathrm{NH}_{2} \mathrm{CuBr}_{2} \mathrm{I}$ enabled carrier concentrations of $\sim 10^{20} \mathrm{~cm}^{-3}$ and power factors up to $1.9 \mathrm{mV} \mathrm{m}^{-2} \mathrm{~K}^{-1}$ (Liu et al., 2017). Tin and germanium perovskites open up the possibility of using selfdoping processes of $\mathrm{Sn}^{2+}$ and $\mathrm{Ge}^{2+}$ to $\mathrm{Sn}^{4+}$ and $\mathrm{Ge}^{4+}$ to achieve electrical conductivities $>100 \mathrm{~S} \mathrm{~cm}^{-1}$ (Takahashi et al., 2013). The electrical conductivity of $\mathrm{Cs}_{3} \mathrm{SnI}_{3}$ thin films has been enhanced through the self-doping mechanism to achieve the highest $z T$ values of this class of material of 0.14 (Lee et al., 2017; Liu et al., 2019b; Saini et al., 2019). Many challenges remain in realising the 
full thermoelectric potential of halide perovskite, but there are promising candidates for low temperature applications.

\section{CARBON NANOTUBE BASED COMPOSITES}

Polymer (nano) composites offer a new route to decouple the interrelated thermoelectric parameters. Therefore, conductive polymer nanocomposites have recently been largely explored as thermoelectric materials. The main strategies have been the combination of (conductive) polymers with inorganic thermoelectric (nano)particles (e.g., p- and n-type $\mathrm{Bi}_{2} \mathrm{Te}_{3}$ ) (Zhang et al., 2010) as well as polymer composites based on carbon nanomaterials (Kim et al., 2010; Wang et al., 2015). Among carbon nanomaterials, carbon nanotubes (CNTs) have attracted the most attention, being a "one-dimensional material" (Hicks and Dresselhaus, 1993). Specifically, the power factor of CNTs can be dramatically increased by enhancing the mobility along the tube direction. Theoretically, the Seebeck coefficient of semiconducting single-wall CNTs (SWCNTs) can reach a value larger than $2000 \mu \mathrm{V} \mathrm{K}^{-1}$ at room temperature as the tube diameter decreases to $0.6 \mathrm{~nm}$ (see Figure 3) (Hung et al., 2015). When combined with a polymer matrix, the intrinsically high electrical conductivity can be retained while reducing the high thermal conductivity due to the presence of the polymer.

The most direct benefit of the presence of the polymer matrix is the reduction in thermal conductivity. For example, Chuizhou et al. reported an in-situ chemically polymerised polyaniline (PANI) layer, uniformly coated on a freestanding CNT network containing randomly entangled individual CNTs and CNT bundles (Meng et al., 2010). The thermal conductivity of the $20 \mathrm{wt} \% \mathrm{PANI} / \mathrm{CNT}$ composites dropped to $\sim 0.5 \mathrm{~W} \mathrm{~m}^{-1} \mathrm{~K}^{-1}$ close to that of PANI $\left(\sim 0.45 \mathrm{~W} \mathrm{~m}^{-1} \mathrm{~K}^{-1}\right)$ with the electrical conductivity of $60 \mathrm{~S} \mathrm{~cm}^{-1}$ and the Seebeck coefficient of $28 \mu \mathrm{V} \mathrm{K} \mathrm{K}^{-1}$. Kim et al. reported a segregated network composites of CNTs/PEDOT:PSS with vinyl acetate ethylene copolymer (Kim et al., 2010). The dissimilar bonding and vibrational spectra between CNT and PEDOT:PSS along with the segregation by vinyl acetate ethylene copolymer, reduced the thermal conductivity of the composites to $0.3 \mathrm{~W} \mathrm{~m}^{-1} \mathrm{~K}^{-1}$. The interconnected network morphology (colloidal PEDOT:PSS particles bridging CNT-CNT junctions) guaranteed an electrical conductivity as high as $400 \mathrm{~S} \mathrm{~cm}^{-1}$ with $35 \mathrm{wt} \%$ SWCNTs.

An effective decoupling of electrical conductivity and Seebeck coefficient has also been demonstrated in the carbon-based thermoelectric nanocomposites. For example, in SWCNT/ PEDOT:PSS nanocomposites (Moriarty et al., 2013b), barriers at the SWCNTs/PEDOT:PSS interface preferentially hindered the transport of low-energy charge carriers and only allowed highenergy carriers to pass across the tube junctions, so to increase the mean carrier energy. This SWCNT/PEDOT:PSS showed an increase in electrical conductivity from $500 \mathrm{~S} \mathrm{~cm}^{-1}-4000 \mathrm{~S} \mathrm{~cm}^{-1}$, with the SWCNTs content increasing from 20 to $95 \mathrm{wt} \%$, while the Seebeck coefficient remained relatively unaltered at around
$20 \mu \mathrm{V} \mathrm{K}^{-1}$, resulting in a power factor as high as $140 \mu \mathrm{W} \mathrm{m} \mathrm{m}^{-1} \mathrm{~K}^{-2}$. Similar works that used multi-wall carbon nanotube (MWCNT) and double wall carbon nanotube (DWNT) (Moriarty et al., 2013a), PEDOT:PSS, and additional meso-tetra(4carboxyphenyl)porphine also observed a decoupling between the Seebeck coefficient, electrical conductivity and thermal conductivity. The electrical conductivity of these organic composites increased to approximately $95 \mathrm{~S} \mathrm{~cm}^{-1}$, in the case of MWCNTs and $960 \mathrm{Scm}^{-1}$, in the case of DWNTs, as the concentrations of both the CNTs and PEDOT:PSS were increased. The Seebeck coefficient $\left(\sim 40 \mu \mathrm{V} \mathrm{K}^{-1}\right.$ for MWCNTs and $70 \mu \mathrm{V} \mathrm{K}^{-1}$ for DWNTs) and thermal conductivity $\left(\sim 0.12 \mathrm{~W} \mathrm{~m}^{-1} \mathrm{~K}^{-1}\right)$, however, remained relatively unaffected by the increase in concentration.

The $\pi-\pi$ interactions between CNT and polymer can positively influence the alignment of polymers, affect the polymer structural morphology and further increase its power factor (Bounioux et al., 2013; Wang et al., 2014). Typically, in-situ polymerization of polymers on CNT templates can grow polymers in an ordered manner on the surface of the CNTs. This hybrid structure can increase the effective carrier delocalisation and thus enhance the carrier mobility in conjugated polymers (Yao et al., 2010; Liu et al., 2011). For example, Qin et al. found that CNTs tune the molecular chain arrangement of PANI from a compacted coil to an expanded coil, by using $m$-cresol (Yao et al., 2014b; 2014a). The electrical conductivity of PANI/SWCNTs has been highly increased to $769 \mathrm{~S} \mathrm{~cm}^{-1}$ thus obtaining a maximum power factor of $176 \mu \mathrm{W}$ $\mathrm{m}^{-1} \mathrm{~K}^{-2}$. Combining both in-situ polymerization with the $\mathrm{m}$-cresol solvent processing, the SWCNTs/PANI composite films reached a power factor of $217 \mu \mathrm{W} \mathrm{m}^{-1} \mathrm{~K}^{-2}$ at room temperature (Wang et al., 2016).

Research on layer-by-layer deposition polymer on CNTs has recently shown the ability to easily adjust nanotube distance, density, and film thickness, which alters the Seebeck coefficient (Rivadulla et al., 2010). The layered structure seemed to improve carrier mobility, increasing both electrical conductivity and the Seebeck coefficient. Cho et al. reported a $40 \mathrm{PANI} / g r a p h e n e /$ PANI/DWNT quad-layered composite film prepared by the layer-by-layer assembly, as illustrated in Figure 4 (Cho et al., 2015), exhibiting an electrical conductivity of $1080 \mathrm{~S} \mathrm{~cm}^{-1}$ and a Seebeck coefficient of $130 \mu \mathrm{V} \mathrm{K} \mathrm{K}^{-1}$, resulting in a remarkable power factor of $1825 \mu \mathrm{W} \mathrm{m} \mathrm{m}^{-1} \mathrm{~K}^{-2}$. The authors pointed to the continuous 3D PANI-wrapped DWNTs and connected graphene network as the reason for the exceptional performance. By alternately layer-by-layer depositing DWCNTs, stabilized by polyethylenimine (PEI), and graphene stabilized by polyvinylpyrrolidone (PVP), they also reported a high power factor n-type 80-bilayer DWNT-PEI/graphene-PVP composites film (Cho et al., 2016a). In addition to its remarkable power factor of $-190 \mu \mathrm{W} \mathrm{m} \mathrm{m}^{-1} \mathrm{~K}^{-2}$ at room temperature, the highly ordered graphene layers also offered a barrier to gas diffusion, resulting in a relatively air-stable $\mathrm{n}$-type composite film.

The mixture of CNTs with polymers can bring other advantages, such as increased mechanical flexibility and even stretchability to the as-fabricated composites. For example, Cho and Son fabricated a stretchable thermoelectric multilayer film by 

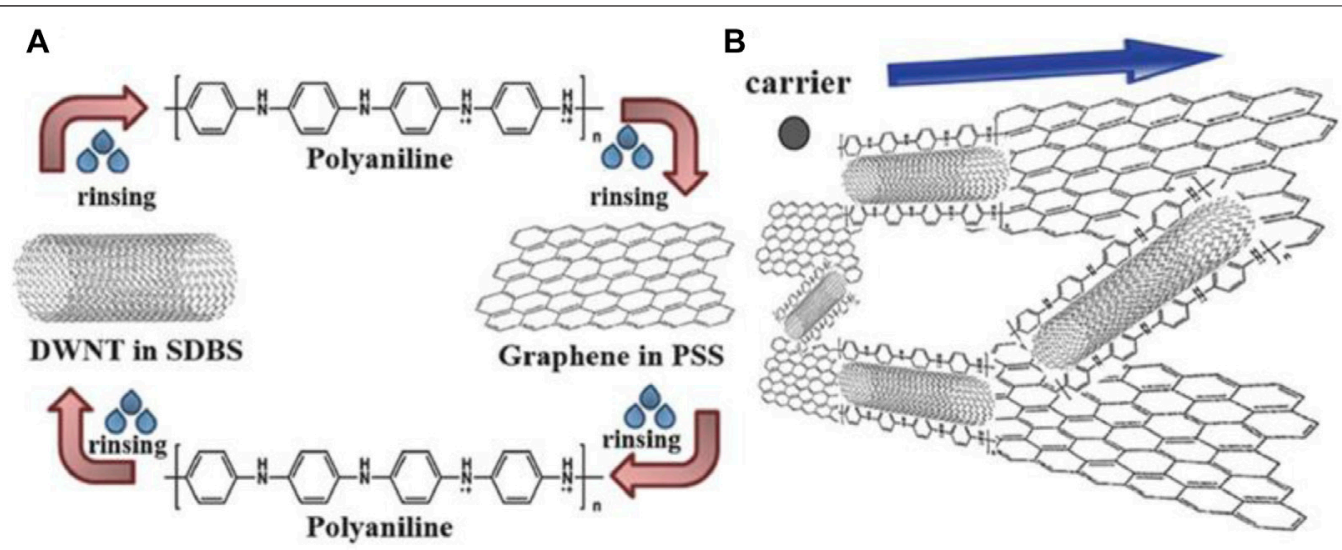

FIGURE 4 | Schematic representations of the layer-by-layer assembly of PANI/graphene/PANI/DWCNT multilayers. (A) The fabrication procedure and (B) carrier transport in the multilayers. Reproduced from Cho et al., 2015 with permission.

alternately depositing $0.1 \mathrm{wt} \%$ polyethylene oxide (PEO) and $0.03 \mathrm{wt} \%$ DWNT, dispersed with $0.1 \mathrm{wt} \%$ polyacrylic acid (PAA) (Cho and Son, 2019). Because of the weak bond strength and high chain mobility between PEO and PAA layers, the PEO/ DWNT-PAA multi-layered composite exhibits a crack-free surface of up to $30 \%$ strain and retains thermoelectric performance of $90 \%$ of the unstretched sample. The resultant 25 bi-layered composite films ( $\sim 500 \mathrm{~nm}$ thick) displayed an electrical conductivity of $19.6 \mathrm{~S}$ $\mathrm{cm}^{-1}$, a Seebeck coefficient of $60 \mu \mathrm{V} \mathrm{K} \mathrm{K}^{-1}$, and attributed to the three-dimensional conjugated network of DWNT.

\section{PERSPECTIVE ON NEXT GENERATION THERMOELECTRIC MATERIALS}

The herein highlighted classes of emerging thermoelectric materials, covering organic polymers, CNT-based thermoelectric composites, inorganic and hybrid organic-inorganic perovskites, have all undergone remarkable progress with many high-performing systems being developed in recent years. While these thermoelectric materials are still in the initial development stage and face a number of challenges, the wide variety of materials and approaches offer many avenues for new material combinations and fine-tuning and optimisation of thermoelectric properties.

Organic and hybrid organic-inorganic materials still suffer from the scarcity of high-performing thermoelectric materials. For the development of next generation state-of-the-art thermoelectric materials, further understanding of the fundamental mechanisms of doping, thermal and electrical transport are required, which is a significant challenge considering the often complex systems with several components and a mixture of ordered and disordered phases. For organic semiconductors, the molecular structure and the morphology of their pristine phases or composites e.g., with CNTs, are also highly important and in many cases difficult to control and understand in detail. For example, a systematic investigation of the critical roles of a conjugated backbone, side chains, and polymer molecular weight relationship with the thermoelectric performance can guide future materials selection. Processing, with its multitude of variable parameters, is likewise an area that will benefit from a better understanding of detailed structureproperty relations for the semiconducting polymer as well as for the possible composite components viewed together. With the ongoing development of tailor-made organic semiconductors for thermoelectric applications, a promising future direction for composite thermoelectrics could be the tailored design of semiconducting polymers with specific interactions with CNTs.

From a technical side, precise measurements of key thermoelectric parameters for organic thermoelectric materials, often prepared as thin polymer films, are different from inorganic bulk materials. Seebeck coefficients and in-plane thermal conductivities reported by different groups are measured by different home-made systems, some of which are affected by environmental conditions, sample size, shape and substrate. Thus, the resulting accuracy and comparability need to be considered. A standard for measuring organic thermoelectric device performance does not exist, due to the various types and structures. More work in this area will undoubtedly be helpful for the continued progress and further development of high-performing thermoelectric systems.

Apart from growing interest in improving the power factor of thermoelectric materials, the mechanical properties of the new generation of emerging thermoelectric materials and composites are attracting particular attention. Efforts should also be dedicated towards new designs for flexible thermoelectric devices and exploring potential applications, taking advantage of positive features like mechanical flexibility while offsetting drawbacks like low efficiency. Finding the right application for new thermoelectric devices using emerging materials classes will ultimately make better use of the unique properties of these promising materials. While not mentioned specifically in this perspective, there are a number of other materials that are also entering the field of thermoelectrics. Here it is worth mentioning crystalline framework materials including metal-organic frameworks and covalent organic frameworks as well as other classes of porous materials such as conjugated microporous 
polymers, gels, and foams. There are still many promising directions for the exploration of materials that are still wide open, making the prospects of thermoelectric materials and devices hugely exciting.

\section{REFERENCES}

Ashraf, R. S., Meager, I., Nikolka, M., Kirkus, M., Planells, M., Schroeder, B. C., et al. (2015). Chalcogenophene Comonomer Comparison in Small Band gap Diketopyrrolopyrrole-Based Conjugated Polymers for High-Performing FieldEffect Transistors and Organic Solar Cells. J. Am. Chem. Soc. 137, 1314-1321. doi:10.1021/ja511984q

Aubry, T. J., Axtell, J. C., Basile, V. M., Winchell, K. J., Lindemuth, J. R., Porter, T. M., et al. (2019). Dodecaborane-Based Dopants Designed to Shield Anion Electrostatics Lead to Increased Carrier Mobility in a Doped Conjugated Polymer. Adv. Mater. 31, 1805647. doi:10.1002/adma.201805647

Aubry, T. J., Winchell, K. J., Salamat, C. Z., Basile, V. M., Lindemuth, J. R., Stauber, J. M., et al. (2020). Tunable Dopants with Intrinsic Counterion Separation Reveal the Effects of Electron Affinity on Dopant Intercalation and Free Carrier Production in Sequentially Doped Conjugated Polymer Films. Adv. Funct. Mater. 30, 2001800-2001813. doi:10.1002/adfm.202001800

Best Research-Cell Efficiency Chart (2021). Natl. Renew. Energy Lab. Available at: https://www.nrel.gov/pv/assets/pdfs/best-research-cell-efficiencies.20200104. pdf (Accessed March 2, 2021)

Bounioux, C., Díaz-Chao, P., Campoy-Quiles, M., Martín-González, M. S., Goñi, A. R., Yerushalmi-Rozen, R., et al. (2013). Thermoelectric Composites of Poly(3-Hexylthiophene) and Carbon Nanotubes with a Large Power Factor. Energy Environ. Sci. 6, 918-925. doi:10.1039/c2ee23406h

Bronstein, H., Nielsen, C. B., Schroeder, B. C., and Mcculloch, I. (2020). The Role of Chemical Design in the Performance of Organic Semiconductors. Nat. Rev. Chem. 4, 66-77. doi:10.1038/s41570-019-0152-9

Brown, S. R., Kauzlarich, S. M., Gascoin, F., and Snyder, G. J. (2006). Yb14MnSb11: New High Efficiency Thermoelectric Material for Power Generation. Chem. Mater. 18, 1873-1877. doi:10.1021/cm060261t

Chang, C., Wu, M., He, D., Pei, Y., Wu, C.-F., Wu, X., et al. (2018). 3D Charge and 2D Phonon Transports Leading to High Out-Of-plane ZT in N-type SnSe Crystals. Science 360, 778-783. doi:10.1126/science.aaq1479

Cho, C., Culebras, M., Wallace, K. L., Song, Y., Holder, K., Hsu, J.-H., et al. (2016a). Stable N-type Thermoelectric Multilayer Thin Films with High Power Factor from Carbonaceous Nanofillers. Nano Energy 28, 426-432. doi:10.1016/ j.nanoen.2016.08.063

Cho, C., and Son, J. (2019). Organic Thermoelectric Multilayers with High Stretchiness. Nanomaterials 10, 41. doi:10.3390/nano10010041

Cho, C., Stevens, B., Hsu, J. H., Bureau, R., Hagen, D. A., Regev, O., et al. (2015). Completely Organic Multilayer Thin Film with Thermoelectric Power Factor Rivaling Inorganic Tellurides. Adv. Mater. 27, 2996-3001. doi:10.1002/ adma.201405738

Cho, C., Wallace, K. L., Tzeng, P., Hsu, J.-H., Yu, C., and Grunlan, J. C. (2016b). Outstanding Low Temperature Thermoelectric Power Factor from Completely Organic Thin Films Enabled by Multidimensional Conjugated Nanomaterials. Adv. Energ. Mater. 6, 1502168. doi:10.1002/aenm.201502168

Cowen, L. M., Atoyo, J., Carnie, M. J., Baran, D., and Schroeder, B. C. (2017). Review-Organic Materials for Thermoelectric Energy Generation. ECS J. Solid State. Sci. Technol. 6, N3080-N3088. doi:10.1149/2.0121703jss

Cramer, C. L., Wang, H., and Ma, K. (2018). Performance of Functionally Graded Thermoelectric Materials and Devices: A Review. J. Electron. Mater. 47, 5122-5132. doi:10.1007/s11664-018-6402-7

Demirbas, A., Hashem, A. A., and Bakhsh, A. A. (2017). The Cost Analysis of Electric Power Generation in Saudi Arabia. Energ. Sourc. B: Econ. Plann. Pol. 12, 591-596. doi:10.1080/15567249.2016.1248874

Deng, S., Saiga, Y., Suekuni, K., and Takabatake, T. (2010). Enhancement of Thermoelectric Efficiency in Type-VIII Clathrate $\mathrm{Ba}_{8} \mathrm{Ga}_{16} \mathrm{Sn}_{30}$ by $\mathrm{Al}$ Substitution for Ga. J. Appl. Phys. 108, 073705. doi:10.1063/1.3490776

Department for Business, Energy and industrial Strategy (2018). Clean Growth Transforming Heating.

\section{AUTHOR CONTRIBUTIONS}

All authors listed have made a substantial, direct, and intellectual contribution to the work and approved it for publication.

Ding, J., Liu, Z., Zhao, W., Jin, W., Xiang, L., Wang, Z., et al. (2019). SeleniumSubstituted Diketopyrrolopyrrole Polymer for High-Performance p-Type Organic Thermoelectric Materials. Angew. Chem. Int. Ed. 58, 18994-18999. doi:10.1002/anie.201911058

Ding, Y. F., Yang, C. Y., Huang, C. X., Lu, Y., Yao, Z. F., Pan, C. K., et al. (2021) Thermally Activated n-Doping of Organic Semiconductors Achieved by NHeterocyclic Carbene Based Dopant. Angew. Chem. Int. Ed. 60, 5816-5820. doi:10.1002/anie.202011537

Dong, B. X., Nowak, C., Onorato, J. W., Ma, T., Niklas, J., Poluektov, O. G., et al. (2021). Complex Relationship between Side-Chain Polarity, Conductivity, and Thermal Stability in Molecularly Doped Conjugated Polymers. Chem. Mater. 33, 741-753. doi:10.1021/acs.chemmater.0c04153

Dong, Q., Fang, Y., Shao, Y., Mulligan, P., Qiu, J., Cao, L., et al. (2015). ElectronHole Diffusion Lengths $>175 \mu \mathrm{m}$ in Solution-Grown $\mathrm{CH}_{3} \mathrm{NH}_{3} \mathrm{PbI}_{3}$ Single Crystals. Science 347, 967-970. doi:10.1126/science.aaa5760

Erickson, K. J., Léonard, F., Stavila, V., Foster, M. E., Spataru, C. D., Jones, R. E., et al. (2015). Thin Film Thermoelectric Metal-Organic Framework with High Seebeck Coefficient and Low thermal Conductivity. Adv. Mater. 27, 3453-3459. doi:10.1002/adma.201501078

Filippetti, A., Caddeo, C., Delugas, P., and Mattoni, A. (2016). Appealing Perspectives of Hybrid Lead-Iodide Perovskites as Thermoelectric Materials. J. Phys. Chem. C 120, 28472-28479. doi:10.1021/ acs.jpcc.6b10278

Finn, P. A., Jacobs, I. E., Armitage, J., Wu, R., Paulsen, B. D., Freeley, M., et al. (2020). Effect of Polar Side Chains on Neutral and P-Doped Polythiophene. J. Mater. Chem. C 8, 16216-16223. doi:10.1039/ d0tc04290k

Forman, C., Muritala, I. K., Pardemann, R., and Meyer, B. (2016). Estimating the Global Waste Heat Potential. Renew. Sust. Energ. Rev. 57, 1568-1579. doi:10.1016/j.rser.2015.12.192

Freer, R., and Powell, A. V. (2020). Realising the Potential of Thermoelectric Technology: A Roadmap. J. Mater. Chem. C 8, 441-463. doi:10.1039/ c9tc05710b

Fu, C., Sun, Y., and Felser, C. (2020). Topological Thermoelectrics. APL Mater. 8, 040913. doi:10.1063/5.0005481

Gascoin, F., Ottensmann, S., Stark, D., Haïle, S. M., and Snyder, G. J. (2005). Zintl Phases as Thermoelectric Materials: Tuned Transport Properties of the Compounds CaxYb1-xZn2Sb2. Adv. Funct. Mater. 15, 1860-1864. doi:10.1002/adfm.200500043

Ge, Z.-H., Zhang, Y.-X., Song, D., Chong, X., Qin, P., Zheng, F., et al. (2018). Excellent ZT Achieved in Cu1.8S Thermoelectric Alloys through Introducing Rare-Earth Trichlorides. J. Mater. Chem. A. 6, 14440-14448. doi:10.1039/ c8ta03195a

Gregory, S. A., Menon, A. K., Ye, S., Seferos, D. S., Reynolds, J. R., Yee, S. K., et al. (2018). Effect of Heteroatom and Doping on the Thermoelectric Properties of Poly(3-alkylchalcogenophenes). Adv. Energ. Mater. 8, 1802419. doi:10.1002/ aenm.201802419

Guo, S.-D., and Wang, J.-L. (2016). Potential Thermoelectric Materials CsMI3 $(\mathrm{M}=\mathrm{Sn}$ and $\mathrm{Pb})$ in Perovskite Structures from First-Principles Calculations. RSC Adv. 6, 101552-101559. doi:10.1039/c6ra14144g

Hamidi-Sakr, A., Biniek, L., Bantignies, J.-L., Maurin, D., Herrmann, L., Leclerc, N., et al. (2017). A Versatile Method to Fabricate Highly In-Plane Aligned Conducting Polymer Films with Anisotropic Charge Transport and Thermoelectric Properties: The Key Role of Alkyl Side Chain Layers on the Doping Mechanism. Adv. Funct. Mater. 27, 1700173. doi:10.1002/ adfm.201700173

Hamidi-Sakr, A., Biniek, L., Fall, S., and Brinkmann, M. (2016). Precise Control of Lamellar Thickness in Highly Oriented Regioregular Poly(3-Hexylthiophene) Thin Films Prepared by High-Temperature Rubbing: Correlations with Optical Properties and Charge Transport. Adv. Funct. Mater. 26, 408-420. doi:10.1002/ adfm.201504096 
Haque, M. A., Kee, S., Villalva, D. R., Ong, W. L., and Baran, D. (2020). Halide Perovskites: Thermal Transport and Prospects for Thermoelectricity. Adv. Sci. 7, 1903389. doi:10.1002/advs.201903389

Haque, M. A., Nugraha, M. I., Paleti, S. H. K., and Baran, D. (2019). Role of Compositional Tuning on Thermoelectric Parameters of Hybrid Halide Perovskites. J. Phys. Chem. C 123, 14928-14933. doi:10.1021/acs.jpcc.9b02830

Harrop, P., and Das, R. (2020). Thermoelectric Energy Harvesting and Sensing 2020-2030 New Principles, New Applications, Forecasts. Available at: https:// www.idtechex.com/en/research-report/thermoelectric-energy-harvesting-andsensing-2020-2030/699.

Hata, T., Giorgi, G., and Yamashita, K. (2016). The Effects of the OrganicInorganic Interactions on the Thermal Transport Properties of $\mathrm{CH}_{3} \mathrm{NH}_{3} \mathrm{PbI}_{3}$. Nano Lett. 16, 2749-2753. doi:10.1021/acs.nanolett.6b00457

He, Y., and Galli, G. (2014). Perovskites for Solar Thermoelectric Applications: A First Principle Study of $\mathrm{CH}_{3} \mathrm{NH}_{3} \mathrm{AI}_{3}(\mathrm{~A}=\mathrm{Pb}$ and $\mathrm{Sn})$. Chem. Mater. 26, 5394-5400. doi:10.1021/cm5026766

Heeney, M., Zhang, W., Crouch, D. J., Chabinyc, M. L., Gordeyev, S., Hamilton, R., et al. (2007). Regioregular Poly(3-Hexyl)selenophene: A Low Band gap Organic Hole Transporting Polymer. Chem. Commun. 47, 5061-5063. doi:10.1039/ b712398a

Hicks, L. D., and Dresselhaus, M. S. (1993). Thermoelectric Figure of merit of a One-Dimensional Conductor. Phys. Rev. B 47, 16631-16634. doi:10.1103/ PhysRevB.47.16631

Hofmann, A. I., Kroon, R., Yu, L., and Müller, C. (2018). Highly Stable Doping of a Polar Polythiophene through Co-processing with Sulfonic Acids and Bistriflimide. J. Mater. Chem. C 6, 6905-6910. doi:10.1039/C8TC01593G

Hung, N. T., Nugraha, A. R. T., Hasdeo, E. H., Dresselhaus, M. S., and Saito, R. (2015). Diameter Dependence of Thermoelectric Power of Semiconducting Carbon Nanotubes. Phys. Rev. B 92, 165426. doi:10.1103/PhysRevB.92.165426

Ichinose, Y., Yoshida, A., Horiuchi, K., Fukuhara, K., Komatsu, N., Gao, W., et al. (2019). Solving the Thermoelectric Trade-Off Problem with Metallic Carbon Nanotubes. Nano Lett. 19, 7370-7376. doi:10.1021/acs.nanolett.9b03022

Jacobs, I. E., Aasen, E. W., Oliveira, J. L., Fonseca, T. N., Roehling, J. D., Li, J., et al. (2016). Comparison of Solution-Mixed and Sequentially Processed P3HT: F4TCNQ Films: Effect of Doping-Induced Aggregation on Film Morphology. J. Mater. Chem. C 4, 3454-3466. doi:10.1039/C5TC04207K

Jacobs, I. E., D’Avino, G., Lin, Y., Lemaur, V., Huang, Y., Ren, X., et al. (2021). Ionexchange Doped Polymers at the Degenerate Limit: What Limits Conductivity at 100\% Doping Efficiency? arXiv. Available at: http://arxiv.org/abs/2101.01714 (Accessed March 2, 2021).

Jacobs, I. E., and Moulé, A. J. (2017). Controlling Molecular Doping in Organic Semiconductors. Adv. Mater. 29, 1703063. doi:10.1002/adma.201703063

Joshi, G., He, R., Engber, M., Samsonidze, G., Pantha, T., Dahal, E., et al. (2014). NbFeSb-based P-type Half-Heuslers for Power Generation Applications. Energ. Environ. Sci. 7, 4070-4076. doi:10.1039/c4ee02180k

Jung, I. H., Hong, C. T., Lee, U.-H., Kang, Y. H., Jang, K.-S., and Cho, S. Y. (2017). High Thermoelectric Power Factor of a Diketopyrrolopyrrole-Based Low Bandgap Polymer via Finely Tuned Doping Engineering. Sci. Rep. 7, 44704. doi:10.1038/srep44704

Kang, K., Schott, S., Venkateshvaran, D., Broch, K., Schweicher, G., Harkin, D., et al. (2019). Investigation of the Thermoelectric Response in Conducting Polymers Doped by Solid-State Diffusion. Mater. Today Phys. 8, 112-122. doi:10.1016/j.mtphys.2019.02.004

Kang, K., Watanabe, S., Broch, K., Sepe, A., Brown, A., Nasrallah, I., et al. (2016). 2D Coherent Charge Transport in Highly Ordered Conducting Polymers Doped by Solid State Diffusion. Nat. Mater. 15, 896-902. doi:10.1038/ nmat 4634

Karpov, Y., Kiriy, N., Al-Hussein, M., Hambsch, M., Beryozkina, T., Bakulev, V., et al. (2018). Hexacyano-[3]-radialene Anion-Radical Salts: a Promising Family of Highly Soluble P-Dopants. Chem. Commun. 54, 307-310. doi:10.1039/ C7CC08671G

Karpov, Y., Kiriy, N., Formanek, P., Hoffmann, C., Beryozkina, T., Hambsch, M., et al. (2020). Sequentially Processed P3HT/CN6-CP $\mathrm{NBu} 4+$ Films: Interfacial or Bulk Doping? Adv. Electron. Mater. 6, 1901346. doi:10.1002/aelm.201901346

Karpov, Y., Kiriy, N., Formanek, P., Zessin, J., Hambsch, M., Mannsfeld, S. C. B., et al. (2019). Layer-by-Layer Assembly Enabled by the Anionic P-Dopant CN6-
CP-K+: a Route to Achieve Interfacial Doping of Organic Semiconductors. ACS Appl. Mater. Inter. 11, 4159-4168. doi:10.1021/acsami.8b15033

Kiefer, D., Kroon, R., Hofmann, A. I., Sun, H., Liu, X., Giovannitti, A., et al. (2019). Double Doping of Conjugated Polymers with Monomer Molecular Dopants. Nat. Mater. 18, 149-155. doi:10.1038/s41563-018-0263-6

Kim, D., Kim, Y., Choi, K., Grunlan, J. C., and Yu, C. (2010). Improved Thermoelectric Behavior of Nanotube-Filled Polymer Composites with Poly(3,4-Ethylenedioxythiophene) Poly(styrenesulfonate). ACS Nano 4, 513-523. doi:10.1021/nn9013577

Kim, G.-H., Shao, L., Zhang, K., and Pipe, K. P. (2013). Engineered Doping of Organic Semiconductors for Enhanced Thermoelectric Efficiency. Nat. Mater. 12, 719-723. doi:10.1038/nmat3635

Kroon, R., Kiefer, D., Stegerer, D., Yu, L., Sommer, M., and Müller, C. (2017). Polar Side Chains Enhance Processability, Electrical Conductivity, and Thermal Stability of a Molecularly P-Doped Polythiophene. Adv. Mater. 29, 1700930. doi:10.1002/adma.201700930

Lalonde, A. D., Pei, Y., Wang, H., and Jeffrey Snyder, G. (2011). Lead telluride alloy Thermoelectrics. Mater. Today 14, 526-532. doi:10.1016/S1369-7021(11) 70278-4

Lawrence Livermore National Laboratory Estimated U'S (2019). Energy Consumption in 2019: 100.2 Quads. Available at: https://flowcharts.llnl.gov/ content/assets/docs/2019_United-States_Energy.pdf.

Lee, C., Hong, J., Stroppa, A., Whangbo, M.-H., and Shim, J. H. (2015). Organicinorganic Hybrid Perovskites ABI3 $\left(\mathrm{A}=\mathrm{CH}_{3} \mathrm{NH}_{3}, \mathrm{NH}_{2} \mathrm{CHNH}_{2} ; \mathrm{B}=\mathrm{Sn}, \mathrm{Pb}\right)$ as Potential Thermoelectric Materials: a Density Functional Evaluation. RSC Adv. 5, 78701-78707. doi:10.1039/c5ra12536g

Lee, W., Li, H., Wong, A. B., Zhang, D., Lai, M., Yu, Y., et al. (2017). Ultralow thermal Conductivity in All-Inorganic Halide Perovskites. Proc. Natl. Acad. Sci. USA 114, 8693-8697. doi:10.1073/pnas.1711744114

Li, D., Gong, Y., Chen, Y., Lin, J., Khan, Q., Zhang, Y., et al. (2020). Recent Progress of Two-Dimensional Thermoelectric Materials. Nano-micro Lett. 12, 36. doi:10.1007/s40820-020-0374-x

Li, J., Rochester, C. W., Jacobs, I. E., Aasen, E. W., Friedrich, S., Stroeve, P., et al. (2016). The Effect of thermal Annealing on Dopant Site Choice in Conjugated Polymers. Org. Elect. 33, 23-31. doi:10.1016/j.orgel.2016.02.029

Li, J., Zhang, G., Holm, D. M., Jacobs, I. E., Yin, B., Stroeve, P., et al. (2015). Introducing Solubility Control for Improved Organic P-type Dopants. Chem. Mater. 27, 5765-5774. doi:10.1021/acs.chemmater.5b02340

Lim, E., Peterson, K. A., Su, G. M., and Chabinyc, M. L. (2018). Thermoelectric Properties of Poly(3-Hexylthiophene) (P3HT) Doped with 2,3,5,6-Tetrafluoro7,7,8,8-Tetracyanoquinodimethane (F4TCNQ) by Vapor-phase Infiltration. Chem. Mater. 30, 998-1010. doi:10.1021/acs.chemmater.7b04849

Liu, J., Sun, J., and Gao, L. (2011). Flexible Single-Walled Carbon Nanotubes/ polyaniline Composite Films and Their Enhanced Thermoelectric Properties. Nanoscale 3, 3616-3619. doi:10.1039/c1nr10386e

Liu, J., van der Zee, B., Alessandri, R., Sami, S., Dong, J., Nugraha, M. I., et al. (2020a). N-type Organic Thermoelectrics: Demonstration of ZT $>0.3$. Nat. Commun. 11, 5694. doi:10.1038/s41467-020-19537-8

Liu, J., Ye, G., Potgieser, H. G. O., Koopmans, M., Sami, S., Nugraha, M. I., et al. (2021). Amphipathic Side Chain of a Conjugated Polymer Optimizes Dopant Location toward Efficient N-Type Organic Thermoelectrics. Adv. Mater. 33, 2006694. doi:10.1002/adma.202006694

Liu, T., Yue, S.-Y., Ratnasingham, S., Degousée, T., Varsini, P., Briscoe, J., et al. (2019a). Unusual Thermal Boundary Resistance in Halide Perovskites: A Way to Tune Ultralow Thermal Conductivity for Thermoelectrics. ACS Appl. Mater. Inter. 11, 47507-47515. doi:10.1021/acsami.9b14174

Liu, T., Zhao, X., Li, J., Liu, Z., Liscio, F., Milita, S., et al. (2019b). Enhanced Control of Self-Doping in Halide Perovskites for Improved Thermoelectric Performance. Nat. Commun. 10, 5750. doi:10.1038/s41467-019-13773-3

Liu, Y., Li, X., Wang, J., Xu, L., and Hu, B. (2017). An Extremely High Power Factor in Seebeck Effects Based on a New N-type Copper-Based Organic/inorganic Hybrid C6H4NH2CuBr2I Film with Metal-like Conductivity. J. Mater. Chem. A 5, 13834-13841. doi:10.1039/c7ta03015k

Liu, Z., Hu, Y., Li, P., Wen, J., He, J., and Gao, X. (2020b). Enhancement of the Thermoelectric Performance of DPP Based Polymers by Introducing One 3,4ethylenedioxythiophene Electron-Rich Building Block. J. Mater. Chem. C 8, 10859-10867. doi:10.1039/d0tc01047b 
Lu, Y., Yu, Z.-D., Liu, Y., Liu, Y.-F., Yang, C.-Y., Yao, Z.-F., et al. (2020). The Critical Role of Dopant Cations in Electrical Conductivity and Thermoelectric Performance of N-Doped Polymers. J. Am. Chem. Soc. 142, 15340-15348. doi:10.1021/jacs.0c05699

Lu, Y., Yu, Z. D., Un, H. I., Un, Z. F., You, H. Y., Jin, W., et al. (2021). Persistent Conjugated Backbone and Disordered Lamellar Packing Impart Polymers with Efficient $\mathrm{n}$-Doping and High Conductivities. Adv. Mater. 33, 2005946-2005947. doi:10.1002/adma.202005946

Ma, L., Lee, W. H., Park, Y. D., Kim, J. S., Lee, H. S., and Cho, K. (2008). High Performance Polythiophene Thin-Film Transistors Doped with Very Small Amounts of an Electron Acceptor. Appl. Phys. Lett. 92, 063310. doi:10.1063/ 1.2883927

Materials for the Energy Transition (2019). Henry Royce Institute. Available at: https://www.royce.ac.uk/materials-for-the-energy-transition/ (Accessed February 27, 2021).

Méndez, H., Heimel, G., Winkler, S., Frisch, J., Opitz, A., Sauer, K., et al. (2015). Charge-transfer Crystallites as Molecular Electrical Dopants. Nat. Commun. 6, 8560. doi:10.1038/ncomms 9560

Meng, C., Liu, C., and Fan, S. (2010). A Promising Approach to Enhanced Thermoelectric Properties Using Carbon Nanotube Networks. Adv. Mater. 22, 535-539. doi:10.1002/adma.200902221

Mettan, X., Pisoni, R., Matus, P., Pisoni, A., Jaćimović, J., Náfrádi, B., et al. (2015). Tuning of the Thermoelectric Figure of Merit of $\mathrm{CH}_{3} \mathrm{NH}_{3} \mathrm{MI}_{3}(\mathrm{M}=\mathrm{Pb}, \mathrm{Sn})$ Photovoltaic Perovskites. J. Phys. Chem. C 119, 11506-11510. doi:10.1021/ acs.jpcc.5b03939

Mikuła, A., Nieroda, P., Mars, K., Dąbrowa, J., and Koleżyński, A. (2020). Structural, Thermoelectric and Stability Studies of Fe-Doped Copper Sulfide. Solid State Ionics 350, 115322. doi:10.1016/ j.ssi.2020.115322

Miyata, K., Atallah, T. L., and Zhu, X.-Y. (2017). Lead Halide Perovskites: Crystalliquid Duality, Phonon Glass Electron Crystals, and Large Polaron Formation. Sci. Adv. 3, e1701469. doi:10.1126/sciadv.1701469

Moriarty, G. P., Briggs, K., Stevens, B., Yu, C., and Grunlan, J. C. (2013a). Fully Organic Nanocomposites with High Thermoelectric Power Factors by Using a Dual-Stabilizer Preparation. Energ. Tech. 1, 265-272. doi:10.1002/ ente.201300018

Moriarty, G. P., De, S., King, P. J., Khan, U., Via, M., King, J. A., et al. (2013b). Thermoelectric Behavior of Organic Thin Film Nanocomposites. J. Polym. Sci. B Polym. Phys. 51, 119-123. doi:10.1002/polb.23186

Murrey, T. L., Riley, M. A., Gonel, G., Antonio, D. D., Filardi, L., Shevchenko, N., et al. (2021). Anion Exchange Doping: Tuning Equilibrium to Increase Doping Efficiency in Semiconducting Polymers. J. Phys. Chem. Lett. 12, 1284-1289. doi:10.1021/acs.jpclett.0c03620

Naab, B. D., Guo, S., Olthof, S., Evans, E. G. B., Wei, P., Millhauser, G. L., et al. (2013). Mechanistic Study on the Solution-phase N-Doping of 1,3-Dimethyl-2Aryl-2,3-Dihydro-1h-Benzoimidazole Derivatives. J. Am. Chem. Soc. 135, 15018-15025. doi:10.1021/ja403906d

Net Zero Emissions Race (2020). Energy and Climate Intelligence Unit. Available at: https://eciu.net/netzerotracker (Accessed February 27, 2021).

Nielsen, C. B., and McCulloch, I. (2013). Recent Advances in Transistor Performance of Polythiophenes. Prog. Polym. Sci. 38, 2053-2069. doi:10.1016/j.progpolymsci.2013.05.003

Nozariasbmarz, A., Agarwal, A., Coutant, Z. A., Hall, M. J., Liu, J., Liu, R., et al. (2017). Thermoelectric Silicides: A Review. Jpn. J. Appl. Phys. 56, 05 DA04. doi:10.7567/JJAP.56.05DA04

Ou, C., Zhang, L., Jing, Q., Narayan, V., and Kar-Narayan, S. (2020). Compositionally Graded Organic-Inorganic Nanocomposites for Enhanced Thermoelectric Performance. Adv. Electron. Mater. 6, 1900720. doi:10.1002/ aelm. 201900720

Paik, J. A., Brandon, E., Caillat, T., Ewell, R., and Fleurial, J. P. (2011). Life Testing of Yb14MnSb11 for High Performance Thermoelectric Couples. Nucl. Emerg. Technol. Sp. 2011, 616-622.

Panchuk, J. R., Laramée, A. W., Manion, J. G., Ye, S., and Seferos, D. S. (2019). Heavy Atom Substitution - A Strategy for Improving Conductivity in Conjugated Polymers. Synth. Met. 253, 57-61. doi:10.1016/ j.synthmet.2019.04.023

Park, J., Yoon, S. E., Kang, Y., Lee, I., Kim, J. H., and Kim, B.-G. (2019). Doping Characteristics of Isoindoloindole-Based Conjugated Polymer toward Robust
Transformable Organic Conductor. Org. Elect. 75, 105435. doi:10.1016/ j.orgel.2019.105435

Patel, S. N., Glaudell, A. M., Peterson, K. A., Thomas, E. M., O’Hara, K. A., Lim, E., et al. (2017). Morphology Controls the Thermoelectric Power Factor of a Doped Semiconducting Polymer. Sci. Adv. 3, e1700434. doi:10.1126/sciadv.1700434

Patra, A., and Bendikov, M. (2010). Polyselenophenes. J. Mater. Chem. 20, 422-433. doi:10.1039/b908983g

Patyk, A. (2010). Thermoelectrics: Impacts on the Environment and Sustainability. J. Electron. Mater. 39, 2023-2028. doi:10.1007/s11664-009-1013-y

Poudel, B., Hao, Q., Ma, Y., Lan, Y., Minnich, A., Yu, B., et al. (2008). Highthermoelectric Performance of Nanostructured Bismuth Antimony telluride Bulk Alloys. Science 320, 634-638. doi:10.1126/science.1156446

Rivadulla, F., Mateo-Mateo, C., and Correa-Duarte, M. A. (2010). Layer-by-layer Polymer Coating of Carbon Nanotubes: Tuning of Electrical Conductivity in Random Networks. J. Am. Chem. Soc. 132, 3751-3755. doi:10.1021/ja910572b

Rogl, G., Grytsiv, A., Yubuta, K., Puchegger, S., Bauer, E., Raju, C., et al. (2015). Indoped Multifilled N-type Skutterudites with ZT $=1.8$. Acta Materialia 95, 201-211. doi:10.1016/j.actamat.2015.05.024

Rogl, G., and Rogl, P. (2019). "Skutterudites: Progress and Challenges," in Novel Thermoelectric Materials and Device Design Concepts. Editors S. Skipidarov and M. Nikitin (Cham: Springer Nature), 177-201. doi:10.1007/978-3-03012057-3_9

Saini, S., Baranwal, A. K., Yabuki, T., Hayase, S., and Miyazaki, K. (2019). Growth of Halide Perovskites Thin Films for Thermoelectric Applications. MRS Adv. 4, 1719-1725. doi:10.1557/adv.2019.279

Saini, S., Baranwal, A. K., Yabuki, T., Hayase, S., and Miyazaki, K. (2020). HybridHalide Perovskite Thin Film Growth for Thermoelectric Applications. J. Electron. Mater.. 49, 2890-2894. doi:10.1007/s11664-020-07958-6

Saska, J., Gonel, G., Bedolla-Valdez, Z. I., Aronow, S. D., Shevchenko, N. E., Dudnik, A. S., et al. (2019). A Freely Soluble, High Electron Affinity Molecular Dopant for Solution Processing of Organic Semiconductors. Chem. Mater. 31, 1500-1506. doi:10.1021/acs.chemmater.8b04150

Scheunemann, D., and Kemerink, M. (2020). Non-Wiedemann-Franz Behavior of the thermal Conductivity of Organic Semiconductors. Phys. Rev. B 101, 75206. doi:10.1103/PhysRevB.101.075206

Scholes, D. T., Hawks, S. A., Yee, P. Y., Wu, H., Lindemuth, J. R., Tolbert, S. H., et al. (2015). Overcoming Film Quality Issues for Conjugated Polymers Doped with F4TCNQ by Solution Sequential Processing: Hall Effect, Structural, and Optical Measurements. J. Phys. Chem. Lett. 6, 4786-4793. doi:10.1021/ acs.jpclett.5b02332

Scholes, D. T., Yee, P. Y., McKeown, G. R., Li, S., Kang, H., Lindemuth, J. R., et al. (2019). Designing Conjugated Polymers for Molecular Doping: The Roles of Crystallinity, Swelling, and Conductivity in Sequentially-Doped SelenopheneBased Copolymers. Chem. Mater. 31, 73-82. doi:10.1021/ acs.chemmater.8b02648

Shin, Y.-h., Komber, H., Caiola, D., Cassinelli, M., Sun, H., Stegerer, D., et al. (2020). Synthesis and Aggregation Behavior of a Glycolated Naphthalene Diimide Bithiophene Copolymer for Application in Low-Level N-Doped Organic Thermoelectrics. Macromolecules 53, 5158-5168. doi:10.1021/ acs.macromol.0c00657

Shukla, A., Sharma, V. K., Gupta, S. K., and Verma, A. S. (2020). Computational Determination of the Physical-Thermoelectric Parameters of Tin-Based Organomatallic Halide Perovskites (CH3NH3SnX3, X $=\mathrm{Br}$ and I): Emerging Materials for Optoelectronic Devices. Mater. Chem. Phys. 253, 123389. doi:10.1016/j.matchemphys.2020.123389

Sierra, J. F., Neumann, I., Cuppens, J., Raes, B., Costache, M. V., and Valenzuela, S. O. (2018). Thermoelectric Spin Voltage in Graphene. Nat. Nanotech. 13, 107-111. doi:10.1038/s41565-017-0015-9

Statz, M., Schneider, S., Berger, F. J., Lai, L., Wood, W. A., Abdi-Jalebi, M., et al. (2020). Charge and Thermoelectric Transport in Polymer-Sorted Semiconducting Single-Walled Carbon Nanotube Networks. ACS Nano 14, 15552-15565. doi:10.1021/acsnano.0c06181

Stoumpos, C. C., Malliakas, C. D., and Kanatzidis, M. G. (2013). Semiconducting Tin and lead Iodide Perovskites with Organic Cations: Phase Transitions, High Mobilities, and Near-Infrared Photoluminescent Properties. Inorg. Chem. 52, 9019-9038. doi:10.1021/ic401215x

Sun, L., Liao, B., Sheberla, D., Kraemer, D., Zhou, J., Stach, E. A., et al. (2017). A Microporous and Naturally Nanostructured Thermoelectric Metal-Organic 
Framework with Ultralow Thermal Conductivity. Joule 1, 168-177. doi:10.1016/j.joule.2017.07.018

Takahashi, Y., Hasegawa, H., Takahashi, Y., and Inabe, T. (2013). Hall Mobility in Tin Iodide Perovskite CH3NH3SnI3: Evidence for a Doped Semiconductor. J. Solid State. Chem. 205, 39-43. doi:10.1016/j.jssc.2013.07.008

Tan, G., Shi, F., Hao, S., Zhao, L.-D., Chi, H., Zhang, X., et al. (2016). Nonequilibrium Processing Leads to Record High Thermoelectric Figure of merit in PbTe-SrTe. Nat. Commun. 7, 12167. doi:10.1038/ncomms12167

Tang, W., Zhang, J., Ratnasingham, S., Liscio, F., Chen, K., Liu, T., et al. (2020). Substitutional Doping of Hybrid Organic-Inorganic Perovskite Crystals for Thermoelectrics. J. Mater. Chem. A. 8, 13594-13599. doi:10.1039/d0ta03648j

Torrance, J. B., Vazquez, J. E., Mayerle, J. J., and Lee, V. Y. (1981). Discovery of a Neutral-To-Ionic Phase Transition in Organic Materials. Phys. Rev. Lett. 46, 253-257. doi:10.1103/physrevlett.46.253

Vijayakumar, V., Durand, P., Zeng, H., Untilova, V., Herrmann, L., Algayer, P., et al. (2020). Influence of Dopant Size and Doping Method on the Structure and Thermoelectric Properties of PBTTT Films Doped with F6TCNNQ and F4TCNQ. J. Mater. Chem. C 8, 16470-16482. doi:10.1039/d0tc02828b

Vijayakumar, V., Zaborova, E., Biniek, L., Zeng, H., Herrmann, L., Carvalho, A., et al. (2019a). Effect of Alkyl Side Chain Length on Doping Kinetics, Thermopower, and Charge Transport Properties in Highly Oriented F4TCNQ-Doped PBTTT Films. ACS Appl. Mater. Inter. 11, 4942-4953. doi:10.1021/acsami.8b17594

Vijayakumar, V., Zhong, Y., Untilova, V., Bahri, M., Herrmann, L., Biniek, L., et al. (2019b). Bringing Conducting Polymers to High Order: Toward Conductivities beyond $105 \mathrm{~S} \mathrm{Cm}^{-1}$ and Thermoelectric Power Factors of $2 \mathrm{~mW} \mathrm{M}^{-1} \mathrm{~K}^{-2}$. $A d v$. Energ. Mater. 9, 1900266. doi:10.1002/aenm.201900266

Vining, C. B. (2009). An Inconvenient Truth about Thermoelectrics. Nat. Mater. 8, 83-85. doi:10.1038/nmat2361

Wang, H., Yi, S.-i., Pu, X., and Yu, C. (2015). Simultaneously Improving Electrical Conductivity and Thermopower of Polyaniline Composites by Utilizing Carbon Nanotubes as High Mobility Conduits. ACS Appl. Mater. Inter. 7, 9589-9597. doi:10.1021/acsami.5b01149

Wang, J., Cai, K., Shen, S., and Yin, J. (2014). Preparation and Thermoelectric Properties of Multi-Walled Carbon Nanotubes/polypyrrole Composites. Synth. Met. 195, 132-136. doi:10.1016/j.synthmet.2014.06.003

Wang, L., Yao, Q., Xiao, J., Zeng, K., Qu, S., Shi, W., et al. (2016). Engineered Molecular Chain Ordering in Single-Walled Carbon Nanotubes/Polyaniline Composite Films for High-Performance Organic Thermoelectric Materials. Chem. Asian J. 11, 1804-1810. doi:10.1002/asia.201600212

Wang, Z., Liu, Z., Ning, L., Xiao, M., Yi, Y., Cai, Z., et al. (2018). Charge Mobility Enhancement for Conjugated DPP-Selenophene Polymer by Simply Replacing One Bulky Branching Alkyl Chain with Linear One at Each DPP Unit. Chem. Mater. 30, 3090-3100. doi:10.1021/acs.chemmater.8b01007

Weber, D. (1978). $\mathrm{CH}_{3} \mathrm{NH}_{3} \mathrm{PbX}_{3}$, ein $\mathrm{Pb}(\mathrm{II})$-System mit kubischer Perowskitstruktur/ $\mathrm{CH}_{3} \mathrm{NH}_{3} \mathrm{PbX}_{3}$, a $\mathrm{Pb}$ (II)-System with Cubic Perovskite Structure. Z. Naturforsch. Sect. B J. Chem. Sci. 33, 1443-1445. doi:10.1515/znb-1978-1214

Wells, H. L. (1893). Über die Cäsium- und Kalium-Bleihalogenide. Z. Anorg. Chem. 3, 195-210. doi:10.1002/zaac.18930030124

Wijsboom, Y. H., Patra, A., Zade, S. S., Sheynin, Y., Li, M., Shimon, L. J. W., et al. (2009). Controlling Rigidity and Planarity in Conjugated Polymers: Poly(3,4Ethylenedithioselenophene). Angew. Chem. Int. Ed. 48, 5443-5447. doi:10.1002/anie.200901231

$\mathrm{Xu}, \mathrm{N}$., Xu, Y., and Zhu, J. (2017). Topological Insulators for Thermoelectrics. Npj Quant. Mater. 2, 51. doi:10.1038/s41535-017-0054-3

Yamashita, Y., Tsurumi, J., Ohno, M., Fujimoto, R., Kumagai, S., Kurosawa, T., et al. (2019). Efficient Molecular Doping of Polymeric Semiconductors Driven by Anion Exchange. Nature 572, 634-638. doi:10.1038/s41586-019-1504-9

Yan, X., Xiong, M., Li, J.-T., Zhang, S., Ahmad, Z., Lu, Y., et al. (2019). PyrazineFlanked Diketopyrrolopyrrole (DPP): A New Polymer Building Block for HighPerformance N-type Organic Thermoelectrics. J. Am. Chem. Soc. 141, 20215-20221. doi:10.1021/jacs.9b10107

Yang, C.-Y., Ding, Y.-F., Huang, D., Wang, J., Yao, Z.-F., Huang, C.-X., et al. (2020). A Thermally Activated and Highly Miscible Dopant for N-type Organic Thermoelectrics. Nat. Commun. 11, 3292. doi:10.1038/s41467-020-17063-1

Yao, Q., Chen, L., Zhang, W., Liufu, S., and Chen, X. (2010). Enhanced Thermoelectric Performance of Single-Walled Carbon Nanotubes/ polyaniline Hybrid Nanocomposites. ACS Nano 4, 2445-2451. doi:10.1021/ nn1002562

Yao, Q., Wang, Q., Wang, L., and Chen, L. (2014a). Abnormally Enhanced Thermoelectric Transport Properties of SWNT/PANI Hybrid Films by the Strengthened PANI Molecular Ordering. Energ. Environ. Sci. 7, 3801-3807. doi:10.1039/c4ee01905a

Yao, Q., Wang, Q., Wang, L., Wang, Y., Sun, J., Zeng, H., et al. (2014b). The Synergic Regulation of Conductivity and Seebeck Coefficient in Pure Polyaniline by Chemically Changing the Ordered Degree of Molecular Chains. J. Mater. Chem. A. 2, 2634-2640. doi:10.1039/c3ta14008c

Yoon, S. E., Kang, Y., Noh, S. Y., Park, J., Lee, S. Y., Park, J., et al. (2020a). High Efficiency Doping of Conjugated Polymer for Investigation of Intercorrelation of Thermoelectric Effects with Electrical and Morphological Properties. ACS Appl. Mater. Inter. 12, 1151-1158. doi:10.1021/acsami.9b17825

Yoon, S. E., Park, J., Kwon, J. E., Lee, S. Y., Han, J. M., Go, C. Y., et al. (2020b). Improvement of Electrical Conductivity in Conjugated Polymers through Cascade Doping with Small-Molecular Dopants. Adv. Mater. 32, 2005129. doi:10.1002/adma.202005129

Yue, S.-Y., Zhang, X., Qin, G., Yang, J., and Hu, M. (2016). Insight into the Collective Vibrational Modes Driving Ultralow thermal Conductivity of Perovskite Solar Cells. Phys. Rev. B 94, 115427. doi:10.1103/PhysRevB.94.115427

Zapata-Arteaga, O., Dörling, B., Perevedentsev, A., Martín, J., Reparaz, J. S., and Campoy-quiles, M. (2020). Closing the Stability-Performance Gap in Organic Thermoelectrics by Adjusting the Partial to Integer Charge Transfer Ratio. Macromolecules 53, 609-620. doi:10.1021/acs.macromol.9b02263

Zhang, B., Sun, J., Katz, H. E., Fang, F., and Opila, R. L. (2010). Promising Thermoelectric Properties of Commercial PEDOT:PSS Materials and Their Bi2Te3 Powder Composites. ACS Appl. Mater. Inter. 2, 3170-3178. doi:10.1021/ am100654p

Zhang, F., and Di, C.-a. (2020). Exploring Thermoelectric Materials from High Mobility Organic Semiconductors. Chem. Mater. 32, 2688-2702. doi:10.1021/ acs.chemmater.0c00229

Zhang, J., Song, L., Pedersen, S. H., Yin, H., Hung, L. T., and Iversen, B. B. (2017). Discovery of High-Performance Low-Cost N-type Mg3Sb2-Based Thermoelectric Materials with Multi-valley Conduction Bands. Nat. Commun. 8, 13901. doi:10.1038/ncomms13901

Zhao, L.-D., Lo, S.-H., Zhang, Y., Sun, H., Tan, G., Uher, C., et al. (2014). Ultralow thermal Conductivity and High Thermoelectric Figure of merit in SnSe Crystals. Nature 508, 373-377. doi:10.1038/nature13184

Zhao, T., Wang, D., and Shuai, Z. (2017). Doping Optimization of OrganicInorganic Hybrid Perovskite $\mathrm{CH} 3 \mathrm{NH} 3 \mathrm{PbI} 3$ for High Thermoelectric Efficiency. Synth. Met. 225, 108-114. doi:10.1016/j.synthmet.2017.01.003

Zhou, J., Zhu, H., Liu, T.-H., Song, Q., He, R., Mao, J., et al. (2018). Large Thermoelectric Power Factor from crystal Symmetry-Protected Non-bonding Orbital in HalfHeuslers. Nat. Commun. 9, 1721. doi:10.1038/s41467-018-03866-w

Zhou, W., Fan, Q., Zhang, Q., Cai, L., Li, K., Gu, X., et al. (2017). High-performance and Compact-Designed Flexible Thermoelectric Modules Enabled by a Reticulate Carbon Nanotube Architecture. Nat. Commun. 8, 14886. doi:10.1038/ncomms14886

Conflict of Interest: The authors declare that the research was conducted in the absence of any commercial or financial relationships that could be construed as a potential conflict of interest.

Publisher's Note: All claims expressed in this article are solely those of the authors and do not necessarily represent those of their affiliated organizations, or those of the publisher, the editors and the reviewers. Any product that may be evaluated in this article, or claim that may be made by its manufacturer, is not guaranteed or endorsed by the publisher.

Copyright $\odot 2021$ Finn, Asker, Wan, Bilotti, Fenwick and Nielsen. This is an openaccess article distributed under the terms of the Creative Commons Attribution License (CC BY). The use, distribution or reproduction in other forums is permitted, provided the original author(s) and the copyright owner(s) are credited and that the original publication in this journal is cited, in accordance with accepted academic practice. No use, distribution or reproduction is permitted which does not comply with these terms. 